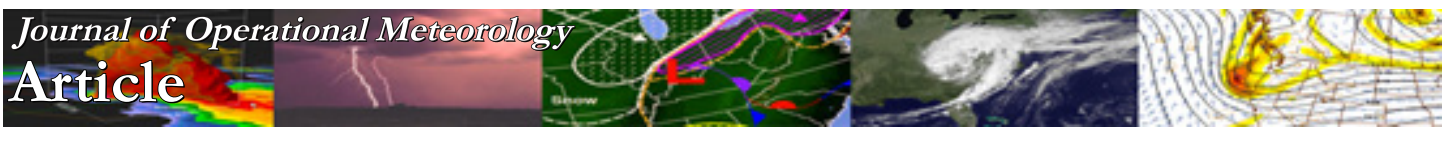

\title{
Forecasting the Inland Extent of Lake Effect Snow Bands Downwind of Lake Ontario
}

\author{
JOSEPH P. VILLANI \\ NOAA/National Weather Service Weather Forecast Office, Albany, New York \\ MICHAEL L. JUREWICZ SR. \\ NOAA/National Weather Service Weather Forecast Office, Binghamton, New York \\ KARIN REINHOLD \\ Department of Mathematics and Statistics, University at Albany, State University of New York, Albany, New York
}

(Manuscript received 22 April 2016; review completed 9 February 2017)

\begin{abstract}
Determining the inland extent (IE) of lake effect snow (LES) is an ongoing operational forecasting challenge at the Albany and Binghamton National Weather Service (NWS) forecast offices, and several other NWS forecast offices in the Great Lakes region. Assuming favorable conditions for development of LES, determining how far inland snow bands will extend is critical to forecasters making decisions supporting the NWS watch/ warning/advisory program and resulting impact-based decision support services.

This research sought to identify which atmospheric parameters commonly have the greatest influence on how far inland LES bands travel, and to develop forecasting techniques to assist meteorologists. Single band LES events for the 2006-2009 winter seasons were examined downwind of Lake Ontario. The IE of LES bands was measured over the duration of each event and broken into quartiles. The quartiles were used to create categories for IE (short, moderate, and long). Several parameters were analyzed, using statistical correlations at data points within, and just outside of, LES bands. Box-and-whiskers plots were constructed for individual parameters relative to each IE category.

The most strongly correlated parameters to IE included existence of a multi-lake/upstream moisture source connection (MLC), mixed-layer (ML) stability (represented by lake-air temperature differentials), 0-1-km bulk shear, and mean ML wind speed. LES bands featuring an MLC showed a greater tendency to progress farther inland, compared to those without. A predictive equation for forecasting IE of LES downwind of Lake Ontario was developed from a statistical model using a stepwise and backwards selection algorithm. A crossvalidation method was used to determine skill.
\end{abstract}

\section{Introduction}

Lake effect snow (LES) is a frequent occurrence during winter seasons downwind of the Great Lakes. Wiggin (1950) first identified atmospheric conditions required for development of LES bands. LES is a mesoscale phenomenon (Peace and Sykes 1966), driven by the overall synoptic flow regime (Niziol 1987). LES bands can be quite narrow (only a few $\mathrm{km}$ wide), making them difficult to forecast and represent in numerical simulations (Lavoie 1972; Ballentine et al. 1998; Steiger et al. 2013). Also, LES bands can produce prolific snowfall, sometimes $>15-30 \mathrm{~cm}$ (6-12 in), with some multi-day events $>150 \mathrm{~cm}$ (60 in) (Sykes 1966).

LES is quite common in Upstate New York, downwind of Lake Ontario. LES is a ubiquitous forecast challenge for the Albany (ALY) and Binghamton (BGM) National Weather Service (NWS) forecast offices (WFOs). The county warning areas (CWA) for ALY and BGM are removed from the lake shore of Ontario, and require forecasters in these offices to not only forecast the existence of potential LES bands, but also how far inland (away from the lake shore) LES bands could extend. Figure 1 shows that the nearest 
point from the Lake Ontario shore to the ALY CWA border is approximately $92 \mathrm{~km}(57 \mathrm{mi})$ and the farthest point is around $338 \mathrm{~km}(210 \mathrm{mi})$, while the nearest point from the Lake Ontario shore to the BGM CWA border is approximately $23 \mathrm{~km}(14 \mathrm{mi})$ and the farthest point is around $264 \mathrm{~km}$ (164 mi).

Much research has been devoted to better understanding the physical processes that govern LES band development in the Great Lakes region over the last 40-50 yr. However, forecasting the inland extent (IE) of such features has received comparatively little, if any, attention. Favorable factors for the development, intensity, and persistence of LES bands have been heavily researched (Dockus 1985; Niziol et al. 1995), and are generally well understood. However, there is substantially less understanding about the processes that modulate the IE of LES bands.

The impetus for this research is the need to be able to more accurately forecast IE of LES bands. Sometimes short distances of only 5-20 km can make the difference between a given location receiving 2.54-5.08 cm (1-2 in) of snow accumulation, versus $8-15 \mathrm{~cm}$ (3-6 in) or even $\geq 30.48 \mathrm{~cm}$ ( $1 \mathrm{ft}$ ) of snowfall. This has critical implications for the NWS watch/warning/advisory program and impact-based decision support services (NWS 2015) that alert people of potentially hazardous weather, such as significant snowfalls. If the factors that determine the IE of LES were better understood, NWS meteorologists would be able to issue more accurate and timely watches, warnings, and advisories for locations farther removed from the lakeshore.

\section{Background}

As mentioned in the introduction, there has been significant research devoted to identifying the physical processes and meteorological factors for the development, intensity, persistence, and general locations of LES bands. Niziol (1987) described how the synoptic environment-with regards to the existence of cyclonic vorticity advection at 850, 700, and $500 \mathrm{hPa}$ - contributes to ascent aiding in LES band formation. Campbell et al. (2016) detailed how the greatest snowfall rates were produced by LES bands that were accompanied by the passage or approach of upper-level short-wave troughs. Hjelmfelt (1990) found that forced orographic ascent enhances LES intensity.

Holroyd (1971) detailed a requirement for a minimum $13^{\circ} \mathrm{C}$ temperature difference between a lake surface and the ambient temperature at $850 \mathrm{hPa}$ to initiate pure LES. Niziol (1987) specified instability classes - based on categories of lake-air temperature differences - to determine potential for LES band development. The conditional instability class is defined as lake- $850-\mathrm{hPa}$ temperature differences between 12 and $17^{\circ} \mathrm{C}$ and lake-700-hPa temperature differences between 17 and $24^{\circ} \mathrm{C}$. The moderate instability class is defined as lake- $850-\mathrm{hPa}$ temperature differences of $\geq 17^{\circ} \mathrm{C}$ and lake-700-hPa temperature differences between 24 and $30^{\circ} \mathrm{C}$. Finally, the extreme instability class is defined as lake-850-hPa temperature differences of $\geq 17^{\circ} \mathrm{C}$ and lake- $700-\mathrm{hPa}$ temperature differences of $\geq 30^{\circ} \mathrm{C}$

Niziol (1987) indicated that wind directions from the boundary layer through $700 \mathrm{hPa}$ (i.e., the steering layer) determine the general locations of LES bands. In addition, Niziol (1987) also explained how changes in wind direction with height through the steering layer (i.e., directional wind shear) determine the persistence of LES bands. If the directional shear is $>30^{\circ}$, single LES bands tend to break apart into multiple bands. If the directional shear is $>60^{\circ}$, LES bands tend to break down completely, resulting in just flurries. This was observed through empirical evidence within mesoscale environments of LES bands (Niziol 1987).

Byrd et al. (1991), through a mobile sounding deployment study in LES storms, showed that mixed layer depths had a much better correlation to LES band intensity - as opposed to simply assessing the degree of instability (measured by the temperature difference between a lake surface and the ambient temperature). The height of a low-level capping inversion is used to denote the top of a mixed layer when determining mixed layer depths. Typical capping inversion heights for most LES bands were found to be in the range of 1-2 km, whereas more intense LES bands had inversion heights of $>3 \mathrm{~km}$ (Niziol 1987). Minder et al. (2015) found that the inland enhancement of snowfall totals was not due to orographic invigoration of convection, which is a potential crucial finding with regards to determining what parameters may or may not modulate IE.

Niziol et al. (1995) classified different types of LES bands. Type I bands, otherwise known as single bands, form when the flow is parallel to the long lake axis, thus covering an extensive fetch over the lake. Single bands are typically $50-200-\mathrm{km}$ long and $20-50-\mathrm{km}$ wide. Type II bands, otherwise known as multi-bands, form when the flow is perpendicular to the long lake axis, with a much shorter fetch over the lake. Multi-bands are typically $20-50-\mathrm{km}$ long and 5-20-km wide. Type III bands are a hybrid of Type I and II bands, exhibiting 
a multi-lake connection (MLC). These Type III LES bands usually develop over upstream lakes, such as Lake Huron or Georgian Bay, and then propagate across Ontario, Canada, before redeveloping over Lakes Erie and Ontario. Steiger et al. (2013) developed a more descriptive term for Type I bands, labeling them long-lake-axis-parallel (LLAP) bands. Veals et al. (2015) developed an updated classification of LES morphology off Lake Ontario based on radar data, and categorized five main types of LES bands: (i) LLAP bands, (ii) broad coverage events that feature opencellular convection or multiple wind-parallel bands produced by horizontal roll convection, (iii) hybrid events that have characteristics of LLAP bands and broad coverage events, (iv) shoreline bands generated by land-breeze convergence during cold, relatively calm conditions near the center of anticyclones, and (v) mesoscale vortices that form during weak flow, often where the lakeshore has a bowl-shaped configuration.

With regards to IE, Niziol et al. (1995) hypothesized that synoptic features - such as surface boundaries or 700-500-hPa short-wave troughs - resulted in higher boundary layer moisture, thus helping sustain LES bands a farther distance inland. However, there have been many cases in which LES bands have extended well inland, despite the absence of such features. On other occasions, conditions appeared favorable (i.e., extreme instability class, high inversion height, little directional shear) for intense LES bands, but the bands remained much closer to the lake shore than expected. Evans and Wagenmaker (2000) examined LES events in Michigan that had an unusually lengthy IE. They found that these events had similarly favorable conditions (to those outlined earlier in this paragraph) for the development and maintenance of significant LES bands. However, features unique to the local area, including the orientation of Lake Michigan, may have contributed to the development of a strong west-to-east lower tropospheric convergence zone that could have influenced the IE.

New operational high-resolution models — such as the High Resolution Rapid Refresh (HRRR; Alexander et al. 2010), the 4-km nest of the North American Mesoscale Model (NAM; Rogers et al. 2014), and the Weather and Research Forecasting (WRF; Skamarock et al. 2008), run locally at NWS forecast offices (e.g., WFO ALY) at similar convection-allowing resolutions $(\leq 5 \mathrm{~km})$ - indicate the potential for LLAP bands in the generally correct space and time, but with limitations. Ballentine and Zaff (2007) showed that the WRF had significant errors in forecasting band characteristics between 6 and $36 \mathrm{~h}$ after model initialization. Also, to this point, no research has been conducted on how well the IE of LES bands is represented by these models. Wright et al. (2013) ran WRF simulations to explore the sensitivity of Great Lakes LES to changes in lakeice cover and surface temperature, but did not explicitly mention the performance of the WRF with regards to IE.

This paper discusses an evaluation of the meteorological factors that contribute most significantly to modulating the IE of LES bands downwind of Lake Ontario. Statistical correlations and box-and-whiskers plots for selected parameters will be presented, and environments conducive to LES bands with farreaching IE of $\geq 62 \mathrm{~km}$ (43 $\mathrm{mi}$ ) (25th percentile IE lengths in the dataset) will be characterized. Last, a predictive equation (developed from a statistical model using stepwise and backwards selection algorithms) for forecasting IE of LES downwind of Lake Ontario will be presented.

\section{Data and Methods}

The main objective of this research was to determine the atmospheric parameters that commonly have the greatest influence on the IE of LES bands. Twenty three single band (LLAP) LES events were studied from 2006 to 2009 downwind of Lake Ontario (Table 1). An event was determined to be any time during the period of study that an LLAP band developed over, or propagated into, any part of the ALY or BGM CWAs. LES band location and IE were determined by using $0.5^{\circ}$ reflectivity from the Montague (KTYX), Albany (KENX), and Binghamton (KBGM) Weather Surveillance Radar-1988 Doppler (WSR-88D) radars (Fig. 1). Six-hour time steps were investigated throughout the duration of each event, coinciding with the 12-km NAM initialization times of 0000, 0600, 1200, and 1800 UTC. This resulted in a total of 95 separate time steps in which LLAP bands were examined. The 12-km NAM analysis soundings for selected points were investigated at 6-h time steps in order to correspond to the model initialization times outlined above. These soundings were generated at selected data points from 12-km NAM $0-\mathrm{hr}$ forecast grids ( 60 vertical levels with model top at $2 \mathrm{hPa}$ ) utilizing the NWS Advanced Weather Information Processing System (AWIPS) sounding display tool. For purpose of sounding investigation, data points were strategically selected relative to observed LES band location based on radar reflectivity. There were 5-7 points per time step depending on the length of LES bands. Points were 
Table 1. List of event dates and corresponding IE maxima of LES bands. Click image for an external version; this applies to all tables and figures hereafter.

\begin{tabular}{|l|l|}
\hline Event dates & Maximum Inland Extent in km (mi) \\
\hline 6-7 February 2006 & $117(110)$ \\
\hline 15 March 2006 & $306(190)$ \\
\hline 29 October 2006 & $208(129)$ \\
\hline 9-10 January 2007 & $315(196)$ \\
\hline 29-30 January 2007 & $80(50)$ \\
\hline 4-5 February 2007 & $150(93)$ \\
\hline 6 February 2007 & $68(42)$ \\
\hline 7-8 February 2007 & $100(62)$ \\
\hline 24 December 2007 & $177(110)$ \\
\hline 19 January 2008 & $113(70)$ \\
\hline 20-21 January 2008 & $114(71)$ \\
\hline 23 January 2008 & $124(77)$ \\
\hline 25-26 January 2008 & $105(65)$ \\
\hline 11 February 2008 & $135(84)$ \\
\hline 17 November 2008 & $233(145)$ \\
\hline 3 January 2009 & $333(207)$ \\
\hline 8-9 January 2009 & $385(239)$ \\
\hline 16-17 January 2009 & $68(42)$ \\
\hline 25 January 2009 & $93(58)$ \\
\hline 20-21 February 2009 & $288(179)$ \\
\hline 24 February 2009 & $323(201)$ \\
\hline 8 April 2009 & $97(60)$ \\
\hline 10-11 December 2009 & $343(213)$ \\
\hline
\end{tabular}

chosen both inside and just outside (north and south) of a LES band (Fig. 2). End points were selected to be just east, northeast, or southeast of where the continuous 15 $\mathrm{dBZ}$ reflectivity terminated. A minimum threshold of $15 \mathrm{dBZ}$ was used to determine a continuous LES band. The use of this 15-dBZ threshold allowed for consistent comparison for each LES event in the study, and also ensured a snowfall rate resulting in measurable snow (Super and Holroyd 1996). In addition, 0000 and 1200 UTC Buffalo (BUF) and Albany, New York (ALB), observed soundings were utilized. Even though the observed soundings from BUF and ALB typically were not as proximal to LES band location as the selected NAM data points, observed sounding data were used so that actual observations were included in the study for comparison to the model-based results.

The IE of LES bands was measured at each of the 95 time steps in the dataset for purposes of recording values of selected parameters. Band length (measured from the Lake Ontario shore inland) and width were determined using $0.5^{\circ}$ reflectivity from the KTYX, KENX, and KBGM WSR-88D radars with a distance measuring tool in AWIPS (Fig. 3). Given that LES bands are relatively shallow features with depths rarely exceeding 2 or $3 \mathrm{~km}$, there is the potential for beam overshooting and underrepresentation of IE somewhat. Brown et al. (2007) discussed this problem specifically for the KTYX radar and found the radar beam can

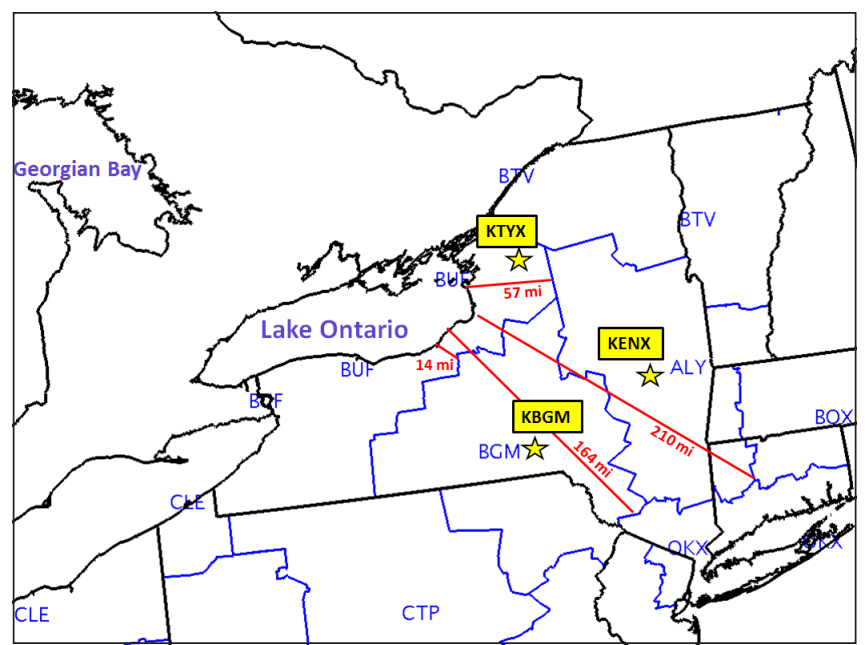

Figure 1. Map of the eastern Great Lakes and Northeast. Blue contours represent NWS county warning areas (CWA). Yellow stars show locations of WSR-88D radar sites. Red lines indicate shortest and farthest distances from Lake Ontario to the edges of the ALY and BGM CWA borders $(1 \mathrm{mi}=1.61 \mathrm{~km})$.

overshoot LES bands with depths of 1-2 km, depending on distance from the radar. The KTYX radar is situated $0.52 \mathrm{~km}$ above the Lake Ontario surface, which can be problematic for beam overshooting (Brown et al. 2007). An attempt was made to mitigate this limitation using ground truth observations; however, observations were determined to be too sparse to supplement when and where overshooting may have occurred. Beam overshooting tends to affect shallower bands and depends on band orientation. This could have an effect on the apparent sensitivity to factors such as inversion height, stability, and wind direction. Inspecting each 6-h time step helped capture the changes in LES band length through the duration of every event. Once IE was determined for each time step in the dataset, categories for IE were developed based on quartiles. The minimum to the 25th percentile was considered short, the 25 th to 75 th percentile was labeled moderate, and the 75 th percentile to the maximum was classified as long.

The chief method involved selecting various parameters to investigate - based on prior LES research (Table 2). The parameters were evaluated at 6-h time intervals $(0000,0600,1200$, and 1800 UTC) for each event. Parameters 1-14 were calculated using the $12-\mathrm{km}$ NAM analysis soundings at selected points. Capping inversion heights were qualitatively determined by observing the thermal profile of the soundings where temperature first ceased decreasing with height. 


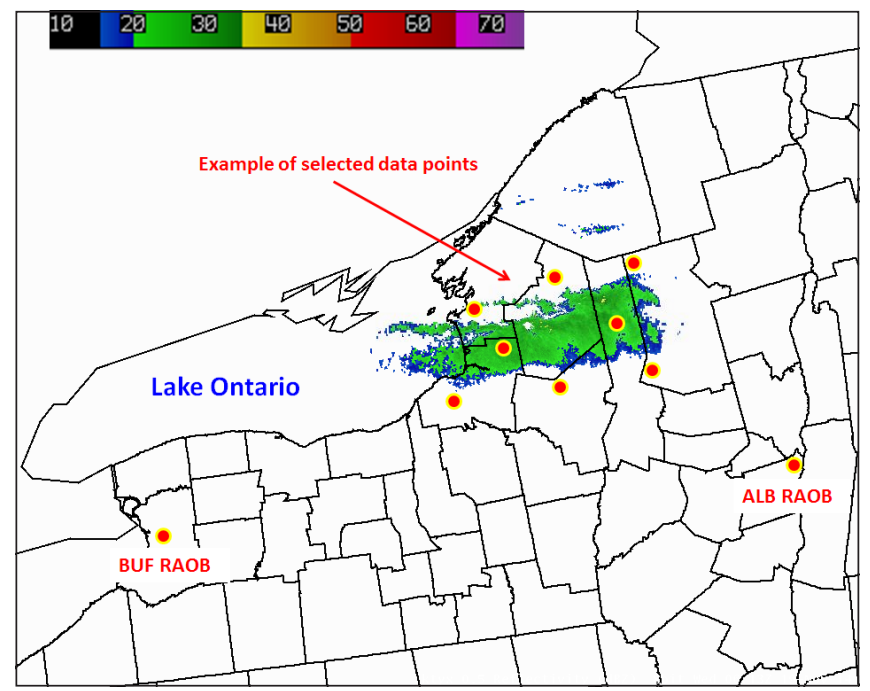

Figure 2. An example of selected model output points relative to a LES band for sounding parameter calculations. LES band depicted by $0.5^{\circ}$ reflectivity from KTYX radar.

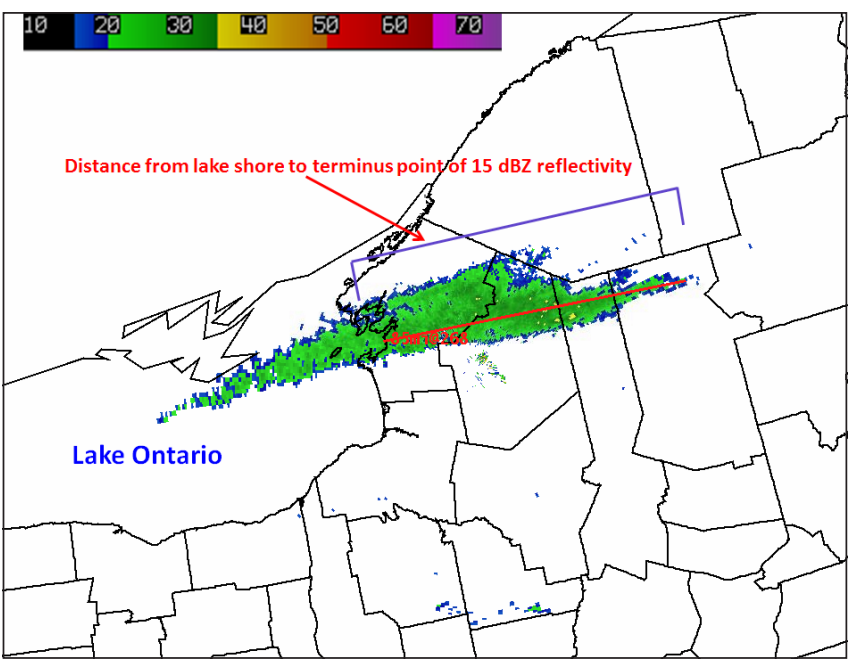

Figure 3. An example of the distance measuring tool, as seen on the NWS AWIPS display, overlaid with $0.5^{\circ}$ reflectivity from KTYX radar. For IE, distance was measured from the lake shore to the end of a continuous band of $\geq 15-\mathrm{dBZ}$ reflectivity, which is $137 \mathrm{~km}$ (85 mi) in this case.

Existence of an MLC (parameter 15) was determined by using satellite imagery (Fig. 4). Visible satellite imagery was used during the daytime, and infrared, along with $11 \mu-3.9 \mu$ satellite imagery, was used at night. LES band length (IE) and width (parameters 16 and 17) were determined using $0.5^{\circ}$ radar reflectivity. Sounding parameter calculations for each point were treated separately and not averaged.

All data for parameter investigation were gathered
Table 2. List of parameters used in the study. The mixed layer (ML) is defined as the vertical layer from the surface to the capping inversion height. One kt = $0.5144 \mathrm{~m} \mathrm{~s}^{-1}$.

\begin{tabular}{|c|c|}
\hline Parameter & \\
\hline 1. & Mean mixed layer ${ }^{1}(\mathrm{ML})$ wind direction $\left(^{\circ}\right)$ \\
\hline 2. & Mean ML wind speed (kt) \\
\hline 3. & Surface dewpoint depression $\left({ }^{\circ} \mathrm{C}\right)$ \\
\hline 4. & Maximum ML dewpoint depression $\left({ }^{\circ} \mathrm{C}\right)$ \\
\hline 5. & Capping inversion height [or ML depth] (km) \\
\hline 6. & Lake - air $\Delta \mathrm{T}$ at $850 \mathrm{hPa}\left({ }^{\circ} \mathrm{C}\right)$ \\
\hline 7. & Lake - air $\Delta \mathrm{T}$ at $700 \mathrm{hPa}\left({ }^{\circ} \mathrm{C}\right)$ \\
\hline 8. & $0-1-\mathrm{km}$ bulk shear $(\mathrm{kt})$ \\
\hline 9. & $0-3-\mathrm{km}$ bulk shear $(\mathrm{kt})$ \\
\hline 10. & ML bulk shear (kt) \\
\hline 11. & Wind direction at top of $\mathrm{ML}\left({ }^{\circ}\right)$ \\
\hline 12. & Wind speed at top of ML (kt) \\
\hline 13. & Surface wind direction $\left({ }^{\circ}\right)$ \\
\hline 14. & Surface wind speed (kt) \\
\hline 15. & Existence of MLC (yes or no) \\
\hline 16. & LES band length (mi) \\
\hline 17. & LES band width (mi) \\
\hline
\end{tabular}

from locally archived NWS AWIPS discs. The data were then loaded onto the Weather Event Simulator (Magsig et al. 2004) for investigation. Events examined were from the NWS ALY and BGM CWAs. Historical water surface temperature data for Lake Ontario were obtained from the Great Lakes Environmental Research Laboratory (coastwatch.glerl.noaa.gov).

The approach for determining the most influential parameters on the IE of LES bands utilized the statistical correlation function in Microsoft Excel ${ }^{\mathrm{TM}}$ spreadsheets in order to compare each parameter's value to the IE of a particular LES band. However, R software (version 3.3.2, www.R-project.org) was used to compute a point biserial correlation for the existence of an MLC (yes $=1$, no $=0$ ) because it is a binary (or categorical) parameter. Box-and-whiskers plots using Microsoft Excel $^{\mathrm{TM}}$ (Banacos 2011) were then constructed for each parameter based on the three categories of IE (short, moderate, long). The box-and-whiskers plots allow for quantifying and classifying parameter values and determining which values are important to the variation of IE. Scatter plots of each parameter versus IE were created using R software.

A predictive equation for IE downwind of Lake Ontario was then developed with $\mathrm{R}$ software (version 3.3.2, www.R-project.org) from a statistical model using stepwise and backwards algorithms. The equation was verified using a cross-validation (CV) method. 


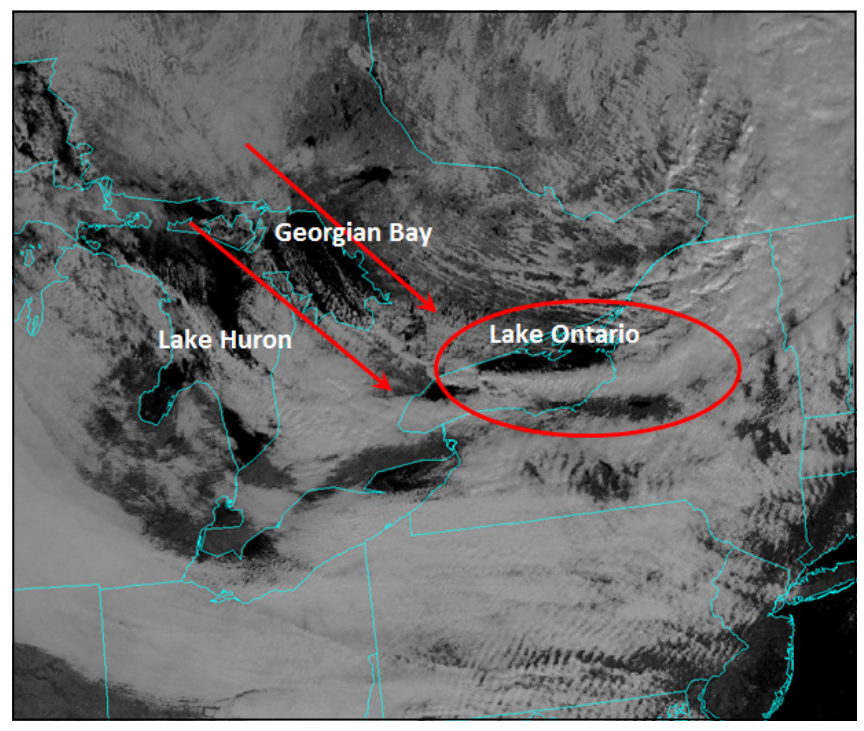

Figure 4. Visible satellite image from 1601 UTC 27 November 2010 that shows a connected moisture plume from Georgian Bay to Lake Ontario.

Additional information regarding development of the statistical model and validation will be discussed in much more detail in section 5 .

Composite plots of mean sea-level pressure (MSLP), as well as geopotential heights at 500, 700, and $850 \mathrm{hPa}$, were created from the North American Regional Reanalysis (NARR) dataset (Mesinger et al. 2006), with composite plots obtained using NOAA's Earth System Research Laboratory (ESRL) website (www.esrl.noaa.gov/psd/cgi-bin/data/narr/plothour.pl).

\section{Results}

\section{a. Model sounding results}

A statistical analysis was performed to identify the parameters that have the greatest influence on the IE of LES bands. The 12-km NAM analysis soundings were used for these correlations based on selected points relative to band location. Sounding parameter calculations for each point were treated separately and not averaged. A two-tailed test was used to determine statistical significance (Wilks 2006). Values for the most strongly correlated parameters were statistically significant to the $99 \%$ level, while correlations for several other parameters were significant to at least the $95 \%$ level. The number of independent data points was considered to be $\mathrm{N}=95$, corresponding to each time step in the study. Even though there were multiple data points for each time step, they were not included in the total number of data points $(\mathrm{N})$ because these points were not independent of each other. These statistics are valid for two-tailed probabilities of correlation coefficient. For $\mathrm{N}=90$, correlation values $(\rho)$ must be $\geq 0.27$ to be considered statistically significant to the 0.01 (or $99 \%$ ) level and $\geq 0.21$ to the 0.05 (or $95 \%$ ) level (Fisher 1925).

Correlations were calculated for all data points, both within and on the periphery of LES bands. Table 3 shows a complete listing of correlation values for all of the parameters. Figure 5 is a graphical representation of how each parameter correlates to IE (band length) and to each other using R software (CRAN.R-project.org/ package $=$ corrplot $).$ Three variables that corresponded to angle measurements (mean ML wind direction, wind direction at top of ML, and surface wind direction) were transformed using cosines. For example, the variable mean ML wind direction was transformed as cosine of the following: mean ML wind direction / $(360 \times 2 \pi)$.

The most strongly correlated parameter to IE was the existence of an MLC ( $\rho=0.64$, Table 3). A point biserial correlation was used to establish the relationship between IE and existence of MLC. The point biserial correlation coefficient is a measurement of the strength of association between a binary variable (taking values 0 or 1 ) and a continuous-valued variable (Glass and Hopkins 1995; Rizopoulos 2006). The scatter plots of IE versus the other variables exhibit the interaction with the categorical variable MLC (Fig. 6). For each scatter plot, there is a clear difference of response in the presence of MLC $=1$. These factors signify that a connection to an upstream moisture source is a key factor in influencing IE. Kristovich et al. (2016) described how the OWLeS (Ontario Winter Lake-effect Systems) field project examined the influences of upstream lakes on LES over Lake Ontario and found that snow particles from Georgian Bay LES and higher-level clouds overspread Lake Ontario lake effect clouds, possibly resulting in natural cloud seeding. Various techniques for forecasting MLC are discussed in section 5.

The temperature difference between the air parcel at $850 \mathrm{hPa}$ and the Lake Ontario water surface had a similarly strong, but negative correlation to $\operatorname{IE}(\rho=-0.65$, Table 3). The strongly negative correlation implies an inverse relationship between the lake-air temperature difference and IE. In other words, greater IE is more effectively correlated with conditional or lower-end moderate instability, rather than extreme instability. For events where higher-end moderate or extreme instability is featured, it is hypothesized that stronger lake-induced instability yields significant snowfall relatively close to the lake shore. The drier environment associated with 


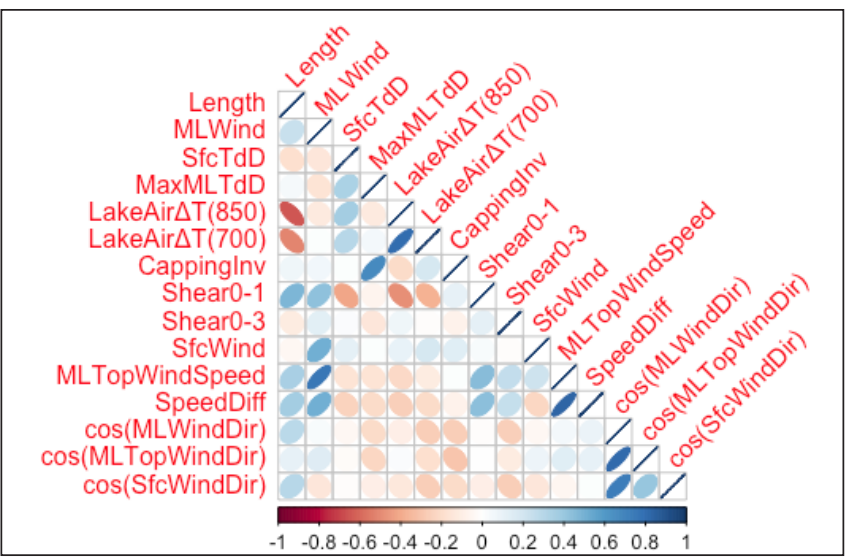

Figure 5. Display of correlation coefficient values between each variable (except MLC). List of abbreviated variables in figure $\left(1 \mathrm{kt}=0.5144 \mathrm{~m} \mathrm{~s}^{-1}\right)$ : Length = LES band length (mi); ML Wind $=$ Mean mixed layer (ML) wind speed (kt); Sfc TdD = Surface dewpoint depression $\left({ }^{\circ} \mathrm{C}\right)$; Max ML TdD = Maximum ML dewpoint depression $\left({ }^{\circ} \mathrm{C}\right)$; Lake Air $\Delta \mathrm{T}(850)=$ Lake $\mathrm{T}-$ air $\mathrm{T}$ at $850 \mathrm{hPa}\left({ }^{\circ} \mathrm{C}\right)$; Lake Air $\Delta \mathrm{T}(700)=$ Lake $\mathrm{T}-$ air $\mathrm{T}$ at $700 \mathrm{hPa}\left({ }^{\circ} \mathrm{C}\right)$; Capping Inv = Capping inversion height [or ML depth] $(\mathrm{km})$; Shear 0-1 = 0-1$\mathrm{km}$ bulk shear $(\mathrm{kt})$; Shear $0-3=0-3-\mathrm{km}$ bulk shear $(\mathrm{kt})$; Sfc Wind $=$ Surface wind speed (kt); ML Top Wind Speed $=$ Wind speed at top of ML (kt); Speed Diff $=$ ML bulk shear (kt); ML Wind Dir = Mean ML wind direction $\left({ }^{\circ}\right)$; ML Top Wind Dir $=$ Wind direction at top of ML $\left(^{\circ}\right)$; Sfc Wind Dir $=$ Surface wind direction $\left({ }^{\circ}\right)$.

Arctic air masses likely limits the downwind extent of such bands. Conversely, in conditional to lower-end moderate instability cases, LES bands tend to extend farther inland because these environments typically lack extreme cold, and thus feature more ambient moisture. The third most strongly correlated parameter was the temperature difference between the air parcel at $700 \mathrm{hPa}$ and the Lake Ontario water surface $(\rho=-0.53)$. This reinforces the notion that an inverse relationship exists between the lake-air temperature difference and IE, up to $700 \mathrm{hPa}$ (or $\sim 3 \mathrm{~km}$ ). The fourth most strongly correlated parameter was $0-1-\mathrm{km}$ bulk shear $(\rho=0.48)$. This indicates that strong vertical wind shear within the layer from the surface to $1 \mathrm{~km}$ also promotes greater IE. A correlation of 0.38 resulted from the ML bulk shear. A very poor correlation with $0-3-\mathrm{km}$ bulk shear (only -0.11 ) accentuates the point that the $0-1-\mathrm{km}$ layer is the most critical for determining IE. The correlation of the mean ML wind speed with IE was 0.24. Although not one of the most strongly correlated parameters to IE,
Table 3. Values of correlation function to IE for model sounding points. Listing is in descending order from most strongly positive to most strongly negative correlation. Parameters in bold are statistically significant to the $99 \%$ level. Parameters in italics are statistically significant to at least the $95 \%$ level.

\begin{tabular}{|c|c|}
\hline Parameter & Correlation to inland extent (model soundings) \\
\hline Existence of MLC & $0.64^{*}$ (point biserial correlation) \\
\hline 0-1-km bulk shear & 0.48 \\
\hline ML bulk shear & 0.38 \\
\hline Wind speed at top of ML & 0.35 \\
\hline Mean ML wind direction & 0.29 \\
\hline Surface wind direction & 0.27 \\
\hline Mean $M L$ wind speed & 0.24 \\
\hline Wind direction at top of ML & 0.11 \\
\hline Capping inversion height (or ML depth) & 0.07 \\
\hline Maximum ML dewpoint depression & 0.04 \\
\hline Surface wind speed & -0.04 \\
\hline $0-3-\mathrm{km}$ bulk shear & -0.11 \\
\hline LES band width & -0.12 \\
\hline Surface dewpoint depression & -0.19 \\
\hline Lake - air $\Delta \mathrm{T}$ at $700 \mathrm{hPa}\left({ }^{\circ} \mathrm{C}\right)$ & -0.53 \\
\hline Lake - air $\Delta \mathrm{T}$ at $850 \mathrm{hPa}$ & -0.65 \\
\hline
\end{tabular}

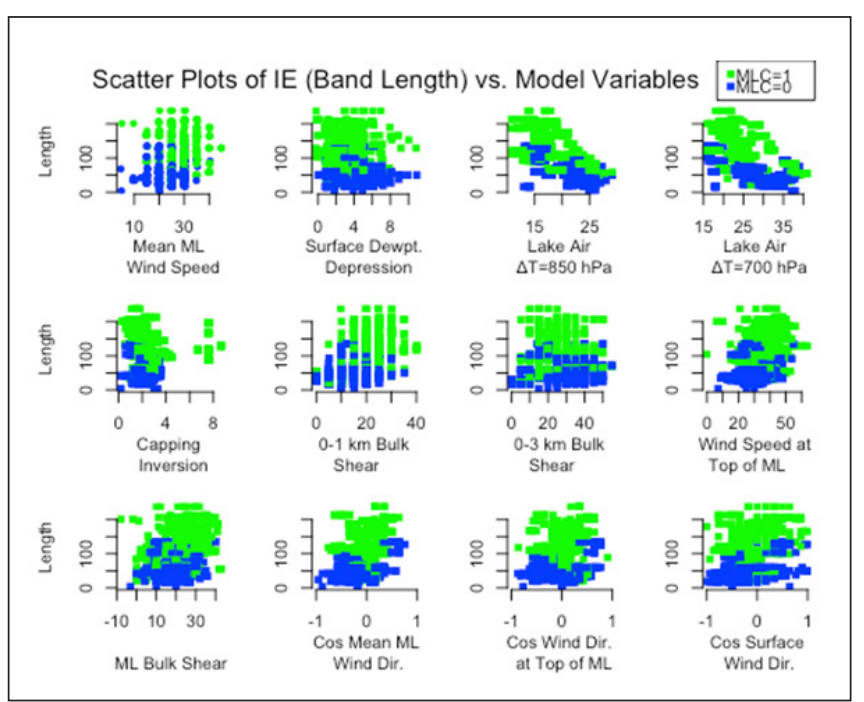

Figure 6. Scatter plots of IE (band length) versus variables in final statistical model, including interaction with MLC. Green points indicate presence of MLC; blue dots indicate MLC not present.

the correlation of mean ML wind speed was statistically significant to the 95\% level (Fisher 1925).

Correlations based on subsets of the data taken from entirely within, or on the periphery of LES bands, were not substantially different from each other-typically with values differing by $<<0.10$. The majority of the selected points from the NAM analysis soundings were taken around the periphery of the model-simulated LES band, with generally two or three points inside a band versus five or six points along the periphery (per 6-h time step). Strictly concerning IE, the implication from a forecasting perspective is the ability to use a model forecast sounding that may be proximate to a LES band 
and possibly within the model-simulated band itself, yielding similar results.

\section{b. Observed sounding results}

Correlations to IE were computed for observed sounding data at BUF and ALB at 0000 and 1200 UTC for the same LES events that were used for the model sounding correlations. Sounding parameter calculations for each point were treated separately and not averaged. Results were similar in terms of which parameters correlated most strongly to IE. Because the correlation to MLC is independent of any sounding data, the value for the point biserial correlation remained the same at 0.64 . The strongest correlated parameter computed from the observed sounding data was the temperature difference between the air parcel at $850 \mathrm{hPa}$ and the Lake Ontario water surface $(\rho=-0.56)$. The second most strongly correlated parameter was the temperature difference between the air parcel at $700 \mathrm{hPa}$ and the Lake Ontario water surface $(\rho=-0.37)$. These results are consistent with the correlations from the model output, further supporting the inverse relationship between the lake-air temperature difference and the IE of LES bands. The third most strongly correlated parameter was the mean ML wind speed $(\rho=0.29)$. This suggests that propagation of a LES band by a relatively fast environmental flow is a key component to long IE.

There were some notable differences between the model and observed sounding correlations (Table 4) that help to explain some of the variations in nearband environment versus the larger-scale environment. One notable discrepancy was the ML bulk shear. The correlation for the observed data was only 0.02 , compared to $\rho=0.38$ for the model output. It is hypothesized that this large difference could be the result of the BUF and ALB soundings generally not being in as close to band location. This implies that it is crucial to sample this parameter in or near a LES band when forecasting IE. This also could be related to the model simulation of the band itself having an impact on the near-band environment. Convergent lowlevel flow near and in the band may locally enhance the bulk shear, which is not so much representative of the environment but a result of the strength of the band itself in the model. Therefore, this parameter may be somewhat tuned to how well the model represents the convergent flow in the band. Another parameter in which a significant difference existed between the model and observed correlations was the maximum ML dewpoint depression. The correlation for the observed
Table 4. Values of correlation function to IE for the ALB and BUF soundings. Listing is in descending order from most strongly positive to most strongly negative correlation. Parameters in bold are statistically significant to the $99 \%$ level. Parameters in italics are statistically significant to at least the $95 \%$ level. Note that the LES band width and existence of an MLC are listed with the same correlation values as in Table 3 because these parameters are independent of sounding data.

\begin{tabular}{|c|c|}
\hline Parameter & $\begin{array}{l}\text { Correlation to inland extent (observed } \\
\text { ALY and BUF soundings) }\end{array}$ \\
\hline Existence of MLC & 0.64* (point biserial correlation) \\
\hline Mean ML wind speed & 0.29 \\
\hline Surface wind speed & 0.26 \\
\hline Wind speed at top of $M L$ & 0.23 \\
\hline Mean ML wind direction & 0.17 \\
\hline Surface wind direction & 0.11 \\
\hline Wind direction at top of ML & 0.10 \\
\hline $0-1-\mathrm{km}$ bulk shear & 0.06 \\
\hline ML bulk shear & 0.02 \\
\hline Capping inversion height (or ML depth) & 0.01 \\
\hline LES band width & -0.12 \\
\hline $0-3-\mathrm{km}$ bulk shear & -0.20 \\
\hline Surface dewpoint depression & -0.20 \\
\hline Maximum ML dewpoint depression & -0.30 \\
\hline Lake - air $\Delta \mathrm{T}$ at $700 \mathrm{hPa}\left({ }^{\circ} \mathrm{C}\right)$ & -0.37 \\
\hline Lake - air $\Delta \mathrm{T}$ at $850 \mathrm{hPa}\left({ }^{\circ} \mathrm{C}\right)$ & -0.56 \\
\hline
\end{tabular}

data was -0.30 , compared to $\rho=0.04$ for the model output. It could be inferred from this discrepancy that farther away from a LES band the ambient dewpoint depression is inversely correlated to the IE. This suggests when model output is used near a modelsimulated band it is typically fairly moist regardless of the IE, thus yielding a low correlation between moisture and IE. However, when the observed data (which are usually further away from the band) are moist, then it is indicative of a larger-scale moist environment. One caveat is that there were a few occasions in the dataset in which LES bands were affecting BUF (Lake Erie bands) and ALB (Lake Ontario bands) around 0000 or 1200 UTC. When assessing the moisture environment for LES IE, forecasters should consider whether model sounding moisture profiles are depicting the large-scale environment or any model-simulated LES. Similarly, if LES bands are observed in the area of an observed sounding, forecasters need to consider whether the radiosonde may have passed through the band and is therefore unrepresentative of the band environment. Refer to Table 4 for a full list of observed sounding correlation values. c. Inland extent categories and box-and-whiskers
plots 
As mentioned in section 3, categories for IE were developed based on quartiles of all IE lengths in the dataset. Results show the short category (minimum to the 25th percentile) had IE lengths from $6 \mathrm{~km}$ (4 mi) to $68 \mathrm{~km}(42 \mathrm{mi})$, the moderate category (25th to 75 th percentile) had IE lengths from $69 \mathrm{~km}$ (43 mi) to 204 $\mathrm{km}(127 \mathrm{mi})$, and the long category (75th percentile to the maximum) had IE lengths from $206 \mathrm{~km}$ (128 mi) to $385 \mathrm{~km}$ (239 mi).

Box-and-whiskers plots (Banacos 2011) were created for each parameter based on the three categories of IE. These box-and-whiskers plots have been included to help quantify and classify which parameters are important to the variation of IE. The height of the box portion is given by the interquartile range of the dataset and extends from the 25 th to 75 th percentile. The horizontal bar within the box denotes the median value. The ends of the whiskers are drawn to the 10th and 90th percentile values. The extreme values are labeled with an " $x$ " at the maximum and minimum points.

The box-and-whiskers plots for the temperature differences between the air parcel at $850 \mathrm{hPa}$ (Fig. 7) and $700 \mathrm{hPa}$ (Fig. 8) and the Lake Ontario water surface show how dramatically IE increases for decreasing temperature differences. In other words, less instability equates to long IE. The box-and-whiskers plots support the high inverse correlation of the Niziol (1987) instability class. The conditional instability class results in long IE, whereas extreme instability class typically yields short IE. Looking at the box-and-whiskers plot for $0-1-\mathrm{km}$ bulk shear, it can be seen that steadily greater values of shear result in progressively larger IE (Fig. 9). The median value of $0-1-\mathrm{km}$ bulk shear for short IE was $7.72 \mathrm{~m} \mathrm{~s}-1$ (15 kt), for moderate IE it was $10.29 \mathrm{~m} \mathrm{~s}-1$ (20 kt), and for long IE it was $12.86 \mathrm{~m}$ $\mathrm{s}-1(25 \mathrm{kt})$. The box-and-whiskers plots substantiate the high correlation of $0-1-\mathrm{km}$ bulk shear to IE.

Figure 10 shows the box-and-whiskers plot for IE based on different scenarios of MLC for (i) when only Lake Ontario is involved (no MLC), (ii) when there is a moisture connection to one upstream lake, and (iii) when there is an MLC with two upstream lakes. The plot indicates that IE increases when an MLC is present, although values were similar for both one and two upstream lakes. This signifies that the number of upstream lakes is not as important as having at least one MLC. Median values for IE increased substantially from $69 \mathrm{~km}$ (43 mi) with no MLC to $200 \mathrm{~km}$ (125 mi) with one upstream lake. Trends in the box-and-whiskers plot for MLC reinforce the strong correlation of MLC to IE.

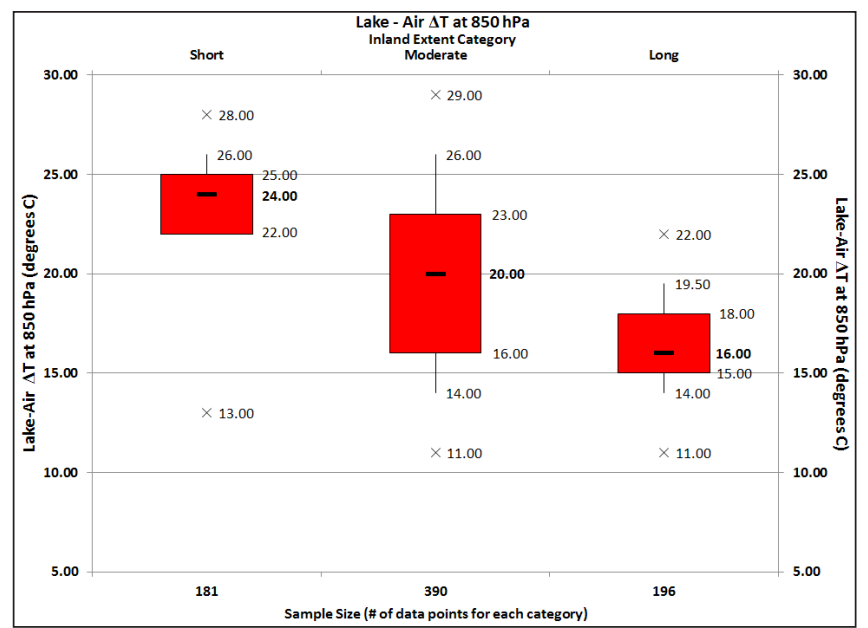

Figure 7. Box-and-whiskers plot of temperature difference between Lake Ontario water surface and the ambient temperature at $850 \mathrm{hPa}$ for each IE category (short/moderate/long).

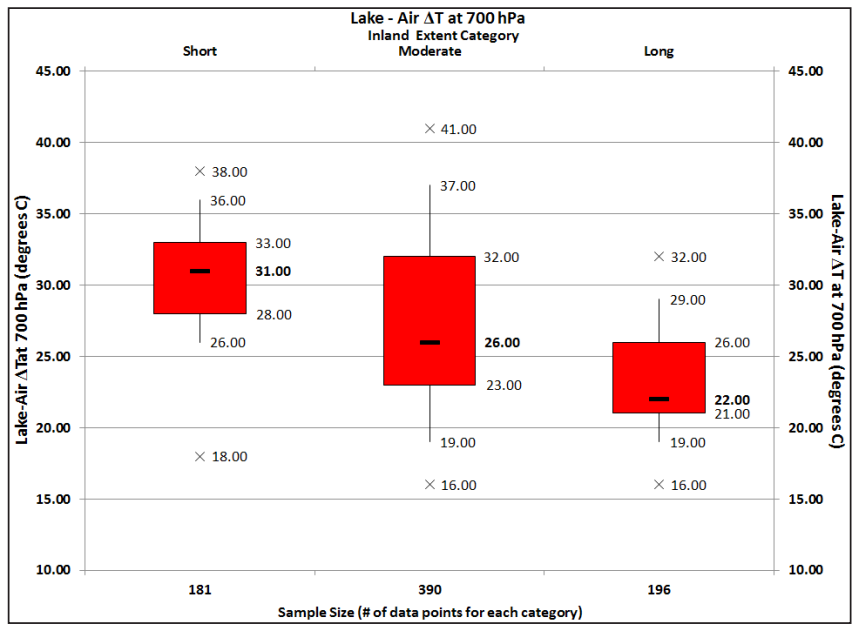

Figure 8. Same as in Fig. 7, except at $700 \mathrm{hPa}$.

Box-and-whiskers plots for the ML bulk shear (Fig. 11), the wind speed at the top of the ML (Fig. 12), and the mean ML wind speed (Fig. 13) all displayed similar results, with trends of increasing winds speeds for each IE category. Median values of wind speed generally increased by about $2.57 \mathrm{~m} \mathrm{~s}-1$ ( $5 \mathrm{kt})$ from short, to moderate, to long IE. Median values of ML depth (Fig. 14) were generally similar between the three categories of IE, ranging from $1.9 \mathrm{~km}$ (short) to $2.5 \mathrm{~km}$ (moderate). However, the maximum ML depth was much greater for long category $(8.7 \mathrm{~km})$ compared to the short $(3.5 \mathrm{~km})$. Also, the long whiskers on the moderate and long categories are indicative of positive skewness of those particular datasets, something not present in the short category. Differences in values between each IE category from box-and-whiskers plots 


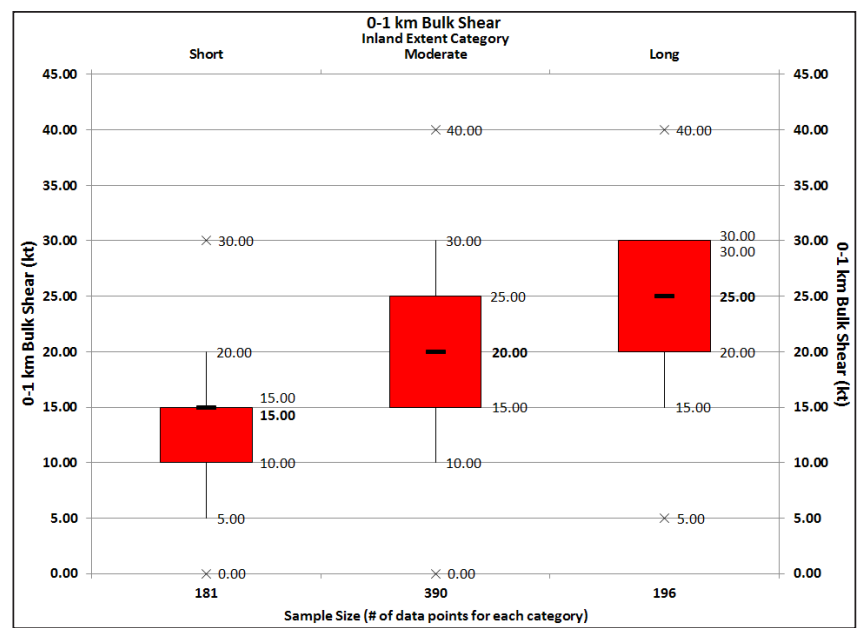

Figure 9. Box-and-whiskers plot of 0-1-km bulk shear for each IE category.

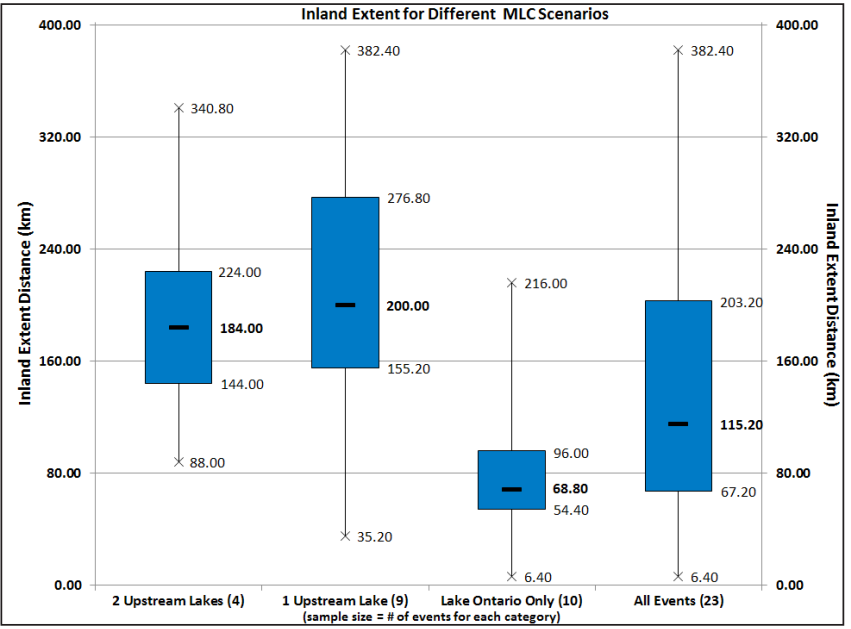

Figure 10. Box-and-whiskers plot of IE for various MLC scenarios (2 upstream lakes, 1 upstream lake, Lake Ontario only, and all events).

for the remaining parameters were not as pronounced, and are considered to be of less operational value (not shown).

\section{d. Favorable and non-favorable environments for moderate to long inland extent}

Based on the most strongly correlated parameters and box-and-whiskers plots, certain environments were observed to promote moderate-to-long IE of LES bands. Such environments included (i) the existence of an MLC from upstream lakes such as Lake Huron and Georgian Bay, (ii) conditional instability class (occasionally moderate, but typically not extreme), (iii) larger magnitudes of $0-1-\mathrm{km}$ bulk shear (weaker shear in 1-3-km layer, based on sounding data), and

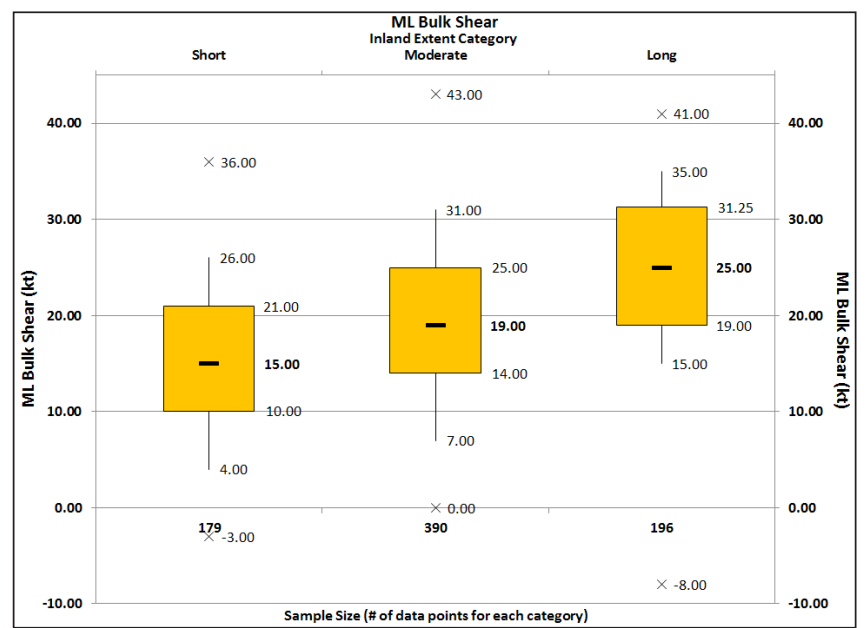

Figure 11. Box-and-whiskers plot of the ML bulk shear for each IE category.

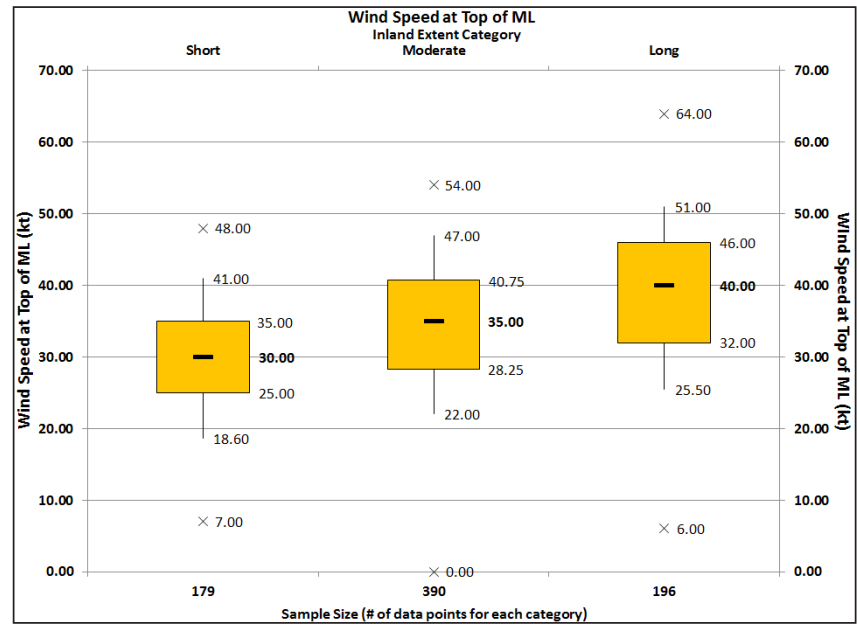

Figure 12. Box-and-whiskers plot of the wind speed at top of the ML for each IE category.

(iv) well-aligned, relatively strong mean flow within the ML (based on statistically significant correlations of wind speed at top of ML, ML bulk shear, and mean ML wind speed). Favorable environments were categorized as Type A, and were characterized by time steps that exhibited conditional instability and the existence of an MLC. Only the first two most strongly correlated parameters were used for simplification. Figure 15a shows an example of a Type A sounding with its respective radar image (Fig. 15b) and IE of the associated LES band (at the time of the sounding in Fig. 15a).

Environments that promoted short IE, with LES bands remaining closer to the lake shore, also were evaluated. Such environments typically included (i) no MLC from upstream lakes, (ii) moderate to extreme 


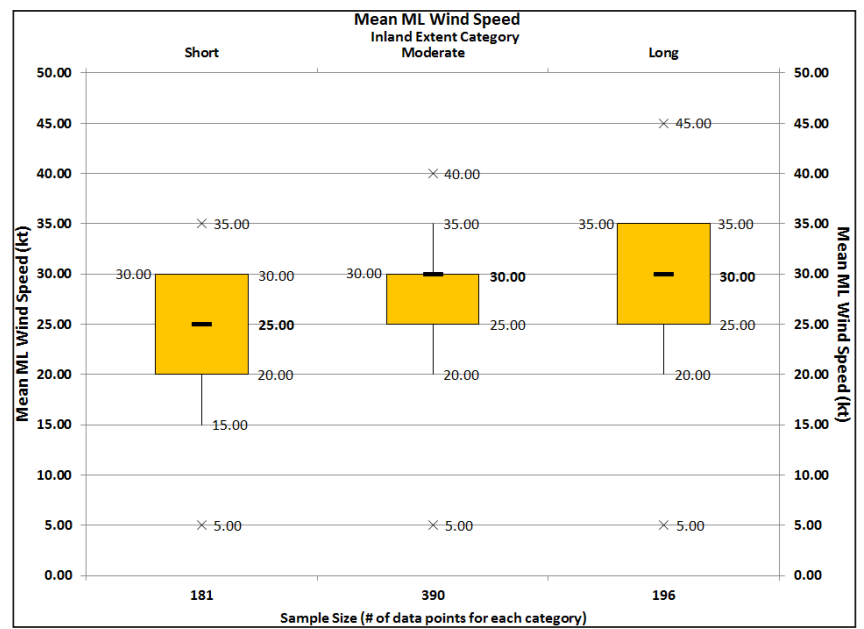

Figure 13. Box-and-whiskers plot of mean ML wind speed for each IE category.

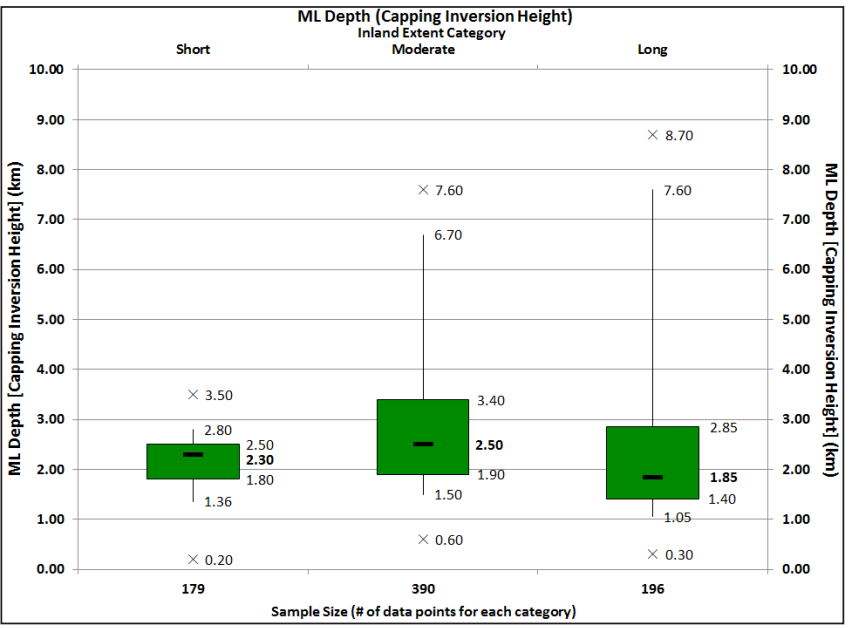

Figure 14. Box-and-whiskers plot of ML depth for each IE category.

instability class, (iii) relatively weak magnitudes of 0-1-km bulk shear (stronger shear in 1-3-km layer, based on sounding data), and (iv) fairly weak mean ML flow. These environments were categorized as Type B and depicted by time steps that exhibited moderate to extreme instability and no MLC present. Figure 16a shows an example of a Type B sounding with its respective radar image (Fig. 16b) and IE of the associated LES band (at the time of the sounding in Fig. 16a). Twenty-six Type A and 33 Type B time steps were identified in the dataset.

Composites of MSLP, as well as geopotential heights at 500, 700, and $850 \mathrm{hPa}$, were created for Type $A$ and $B$ events. NARR composites from ESRL were plotted to include the 0000, 0600, 1200, and 1800 UTC time periods for applicable Type A and B events and times. Some differences are apparent in the Type A (Fig.
17) and Type B (Fig. 18) composites. At $500 \mathrm{hPa}$, the trough located over Ontario and Quebec was negatively tilted in the Type A composite but positively tilted in the Type B composite. At 700 and $850 \mathrm{hPa}$, there is a deeper trough and multiple closed height contours located over Quebec for Type A events, compared to a weaker trough for Type B events. With regards to MSLP, for Type A events low pressure is centered near the mouth of the Saint Lawrence River in southeastern Quebec, whereas for the Type B events the low pressure center is positioned much farther north and high pressure is noticeably stronger across west-central Canada (extending through much of the central and eastern United States). With regards to seasonal trends, Type A events spanned each month from October to March, whereas Type B events only occurred in January and February in this study.

\section{Forecasting Techniques}

\section{a. A predictive equation for the inland extent of LES bands}

Based on results from this research and prior techniques of forecasting LES, a predictive equation was developed to aid meteorologists at NWS ALY and BGM in forecasting the IE of LES bands downwind of Lake Ontario. The output from this predictive equation is the forecast of IE in miles $(1 \mathrm{mi}=1.61 \mathrm{~km})$, with the distance beginning from the shore of Lake Ontario and extending inland.

The predictive equation was developed by selecting a statistical model. First, a full model with all variables, as well as their interactions with MLC, was considered. Classical regression models make strong assumptions on the distribution of the data. Preliminary analyses revealed that the response variable exhibited a degree of skewness to the right that also was reflected in the distribution of the error terms on the full model. BoxCox transformations (Box and Cox 1964; Kutner et al. 2004; Fox 2008) were considered to identify the transformation that stabilized the variance of the error terms and normalized their distribution. The maximumlikelihood estimate for the normalizing power was 0.38 , which is significantly different from 1 (corresponding to no transformation needed) and from 0 (corresponding to $\log$ transform). The response variable in our model was $\mathrm{Y}=(\mathrm{LES}$ band length $) 0.38$.

Next, several methods of model selection were considered.Stepwiseandbackwards selectionalgorithms (Venables and Ripley 2002) were implemented that 


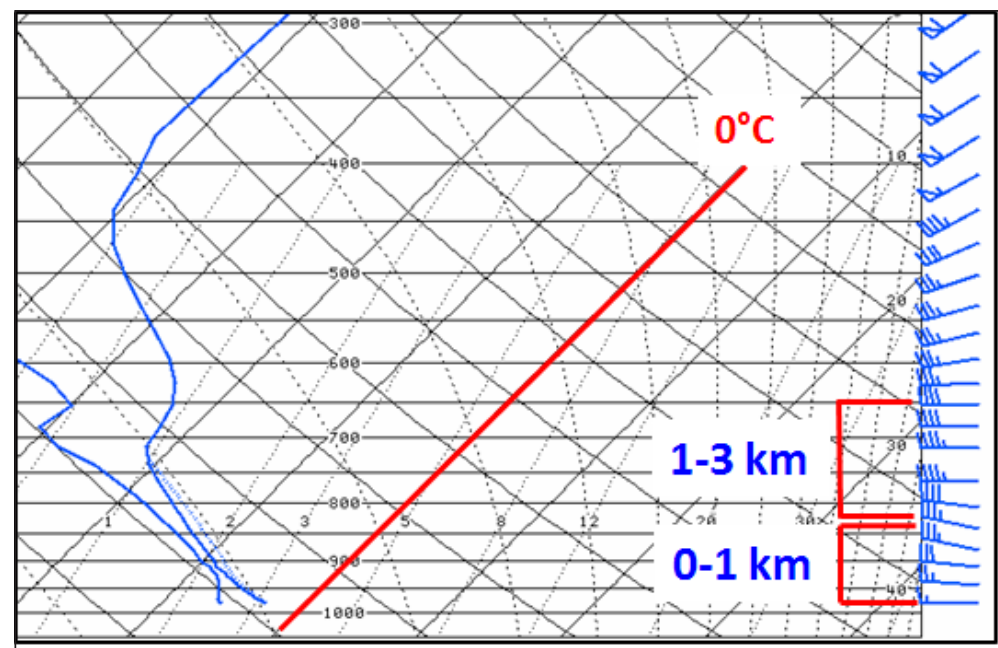

(a)

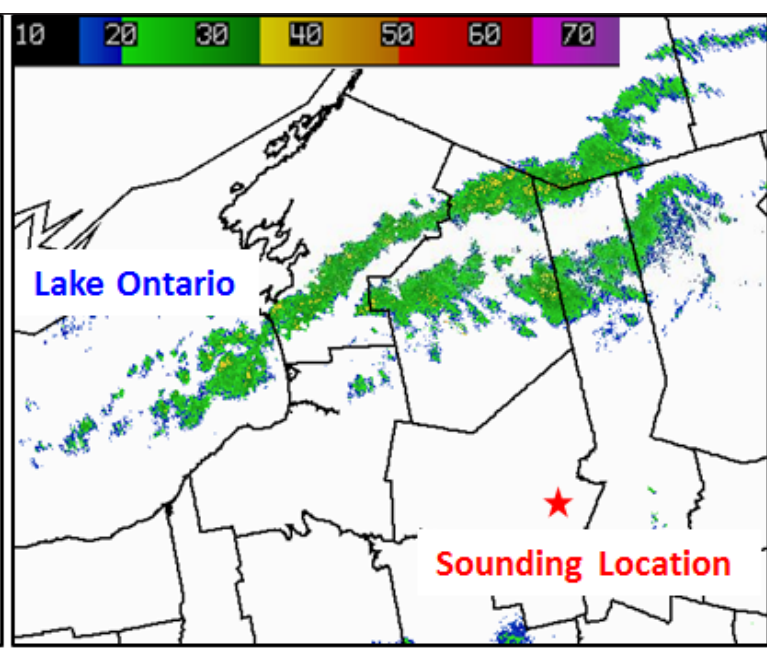

(b)

Figure 15. (a) Example of a Type A sounding (0-h NAM analysis sounding from near KUCA) featuring strong 0-1$\mathrm{km}$ bulk shear (much less in 1-3-km layer) and conditional instability. (b) Associated $0.5^{\circ}$ reflectivity (dBZ) mosaic at the time of the sounding. Sounding and radar image from 1200 UTC 2 January 2012.

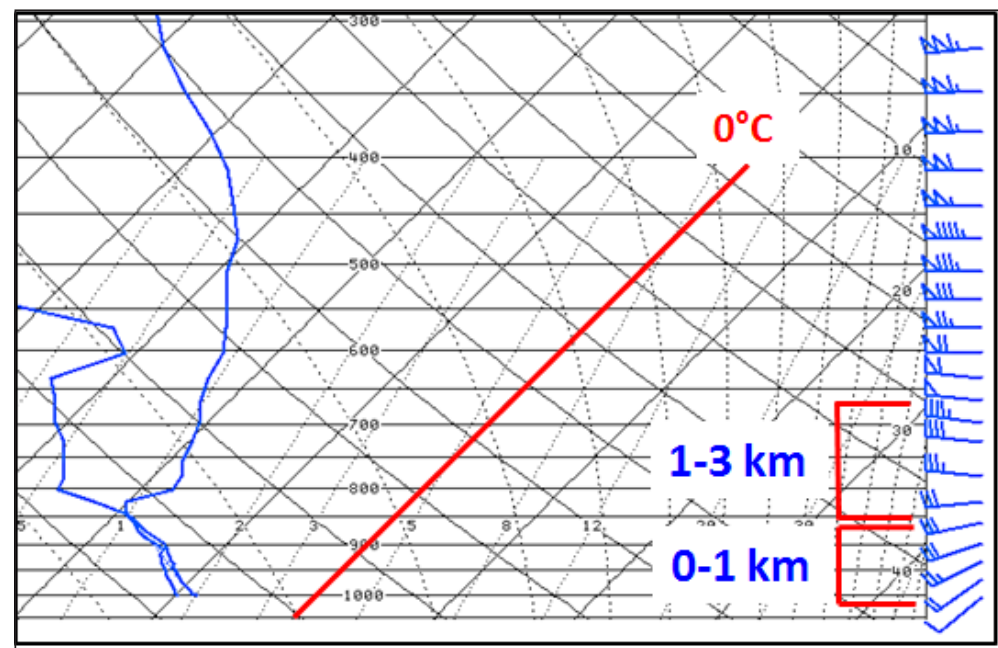

(a)

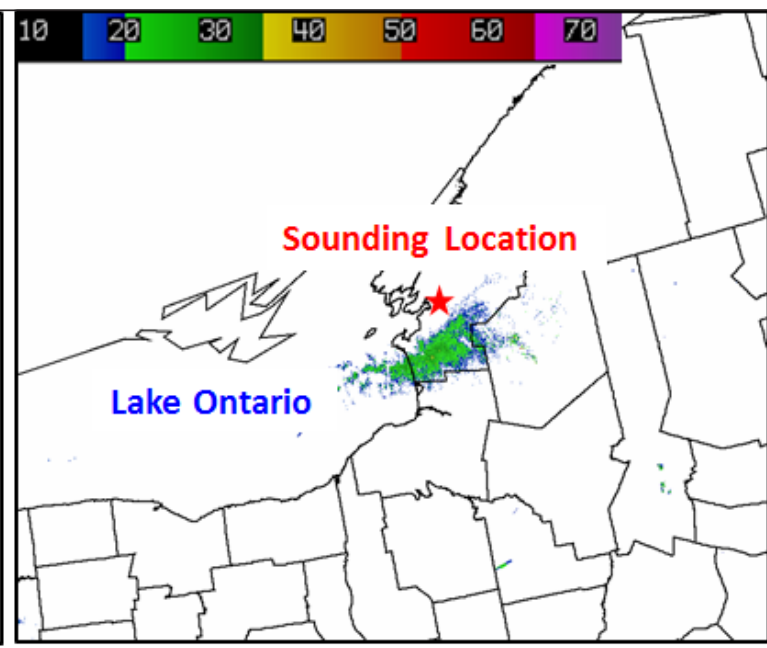

(b)

Figure 16. As in Fig. 15 except for a Type B event from 1200 UTC 8 January 2014.

minimized Akaikes's information criteria (AIC, Akaike 1972), as well as the best-subsets algorithm (CRAN.Rproject.org/package=leaps) that identifies the best models with a fixed number of variables that minimizes AIC. For all models, the standard error (SE), adjusted R2, AIC, Bayesian information coefficient (BIC), Mallow's Cp coefficient, and the predicted residual sum of squares (PRESS) statistic were computed following Kutner et al. (2004). The algorithms were based on the AIC performance measure rather than $p$ values or adjusted R2, or even Mallow's Cp, because models selected under those measures tend to be more biased, whereas models selected by minimizing AIC tend to perform better (Breiman 1988). In the selection of the best subset, models were selected that minimized AIC and at the same time achieved SE, BIC, and PRESS close to their minimum, high R2, and $\mathrm{Cp}$ close to its theoretical expected value. That is, models that performed reasonably well in all measures were selected. There is criticism in the literature that even models based on AIC are biased, and suggest to select models according to CV procedures (Picard and Cook 1984; Breiman 1988; Breiman and Spector 1992). A sequence of CV variable selection algorithms were considered that include the above mentioned procedures (CRAN.R-project.org/package=bestglm), K-fold CV (Hastie et al. 2009), adjusted K-fold CV (Davison and Hinckley 1997), and delete-d CV with 

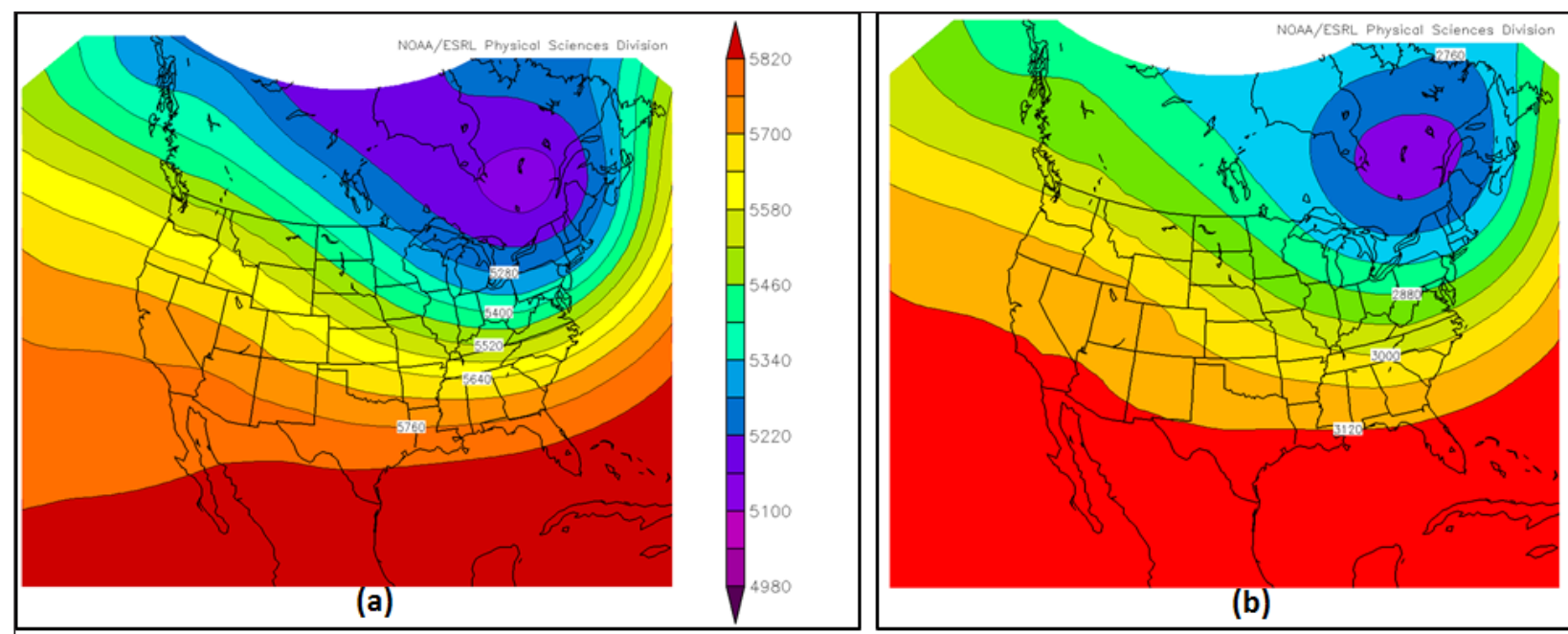

(b)
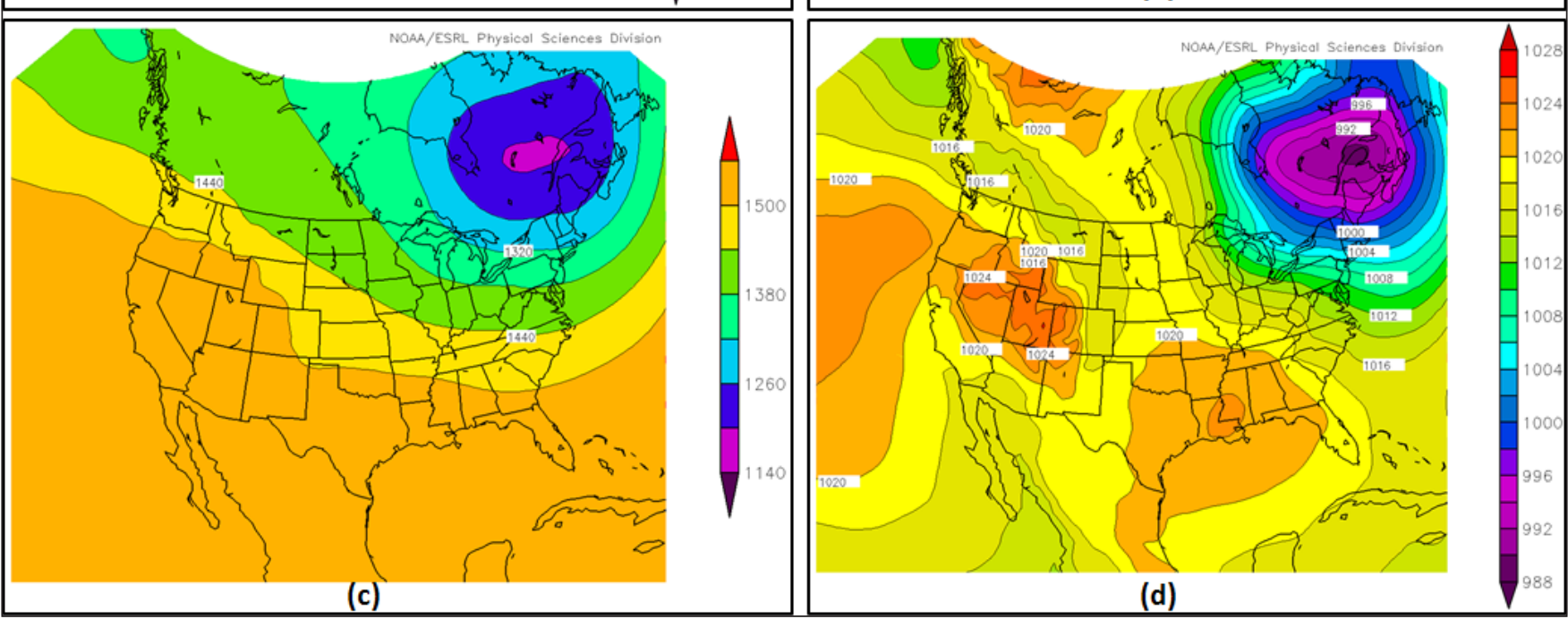

Figure 17. Composites of geopotential height (60-m contour interval) at (a) $500 \mathrm{hPa}$, (b) $700 \mathrm{hPa}$, and (c) $850 \mathrm{hPa}$, and (d) MSLP (2 hPa contour interval), for Type A events using the NARR dataset. Images generated using the NOAA/ESRL Physical Sciences Division website at www.esrl.noaa.gov/psd/cgi-bin/data/narr/plothour.pl.

random subsamples (Shao 1993, 1997).

After all these algorithms were considered (backwards selection, stepwise selection, best subsets, and $\mathrm{CV}$ ) and the models' performance metrics were computed, a final collection of six models resulted, with a number of models that had from 10 to 12 variables plus interactions terms with the categorical variable MLC. To assess the predictive performance of models with the selected variables, 5-folds CV algorithms (CRAN.Rproject.org $/$ package $=$ cvTools) were run and repeated 100 times. Finally, the model that performed best under all metrics and followed the parsimony principle was selected.

The resulting predictive equations based on the statistical model for IE are as follows (where TdD = dewpoint depression):
IE $\left(\right.$ or Band Length $\left.{ }^{0.38}\right)=4.781378-0.041242$ (mean ML wind speed) +0.088804 (surface TdD) 0.100086 (lake T - air T@850hPa) + 0.030905 $(0-1-\mathrm{km}$ bulk shear $)+0.010518 \quad(0-3-\mathrm{km}$ bulk shear) +0.085037 (top of ML wind speed) -0.048156 (ML bulk shear) $+1.746865 \cos ($ mean ML wind dir. $/ 360 \times 2 \pi)-1.059166 \cos ($ top of ML wind dir. $/ 360 \times 2 \pi)+3.193727($ MLC) $+[0.050355$ (mean ML wind speed) $\times$ MLC] $-[0.081214$ (lake T-air T@850hPa) × MLC] + [0.023536 (lake T - air T@700hPa)× MLC] - [0.051691 (ML depth) $\times$ MLC] $-[0.017483(0-3-k m$ bulk shear $) \times$ MLC $]$ $+[0.399647 \cos ($ surface wind $\operatorname{dir} . / 360 \times 2 \pi) \times$ MLC $]-[0.103989$ (top of ML wind speed) $\times$ MLC $]$ $+[0.080021$ (ML bulk shear) $\times$ MLC $]$; 

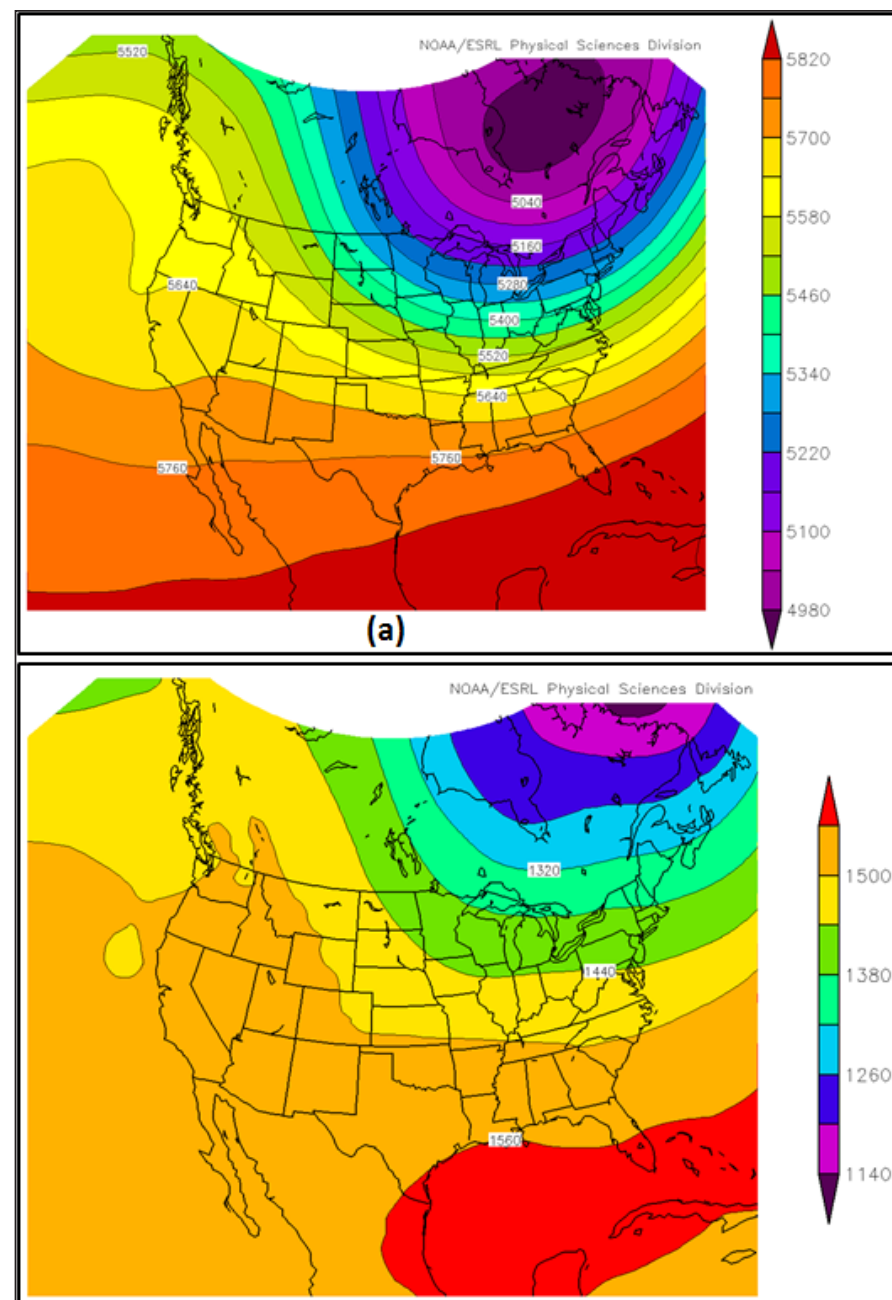

(c)
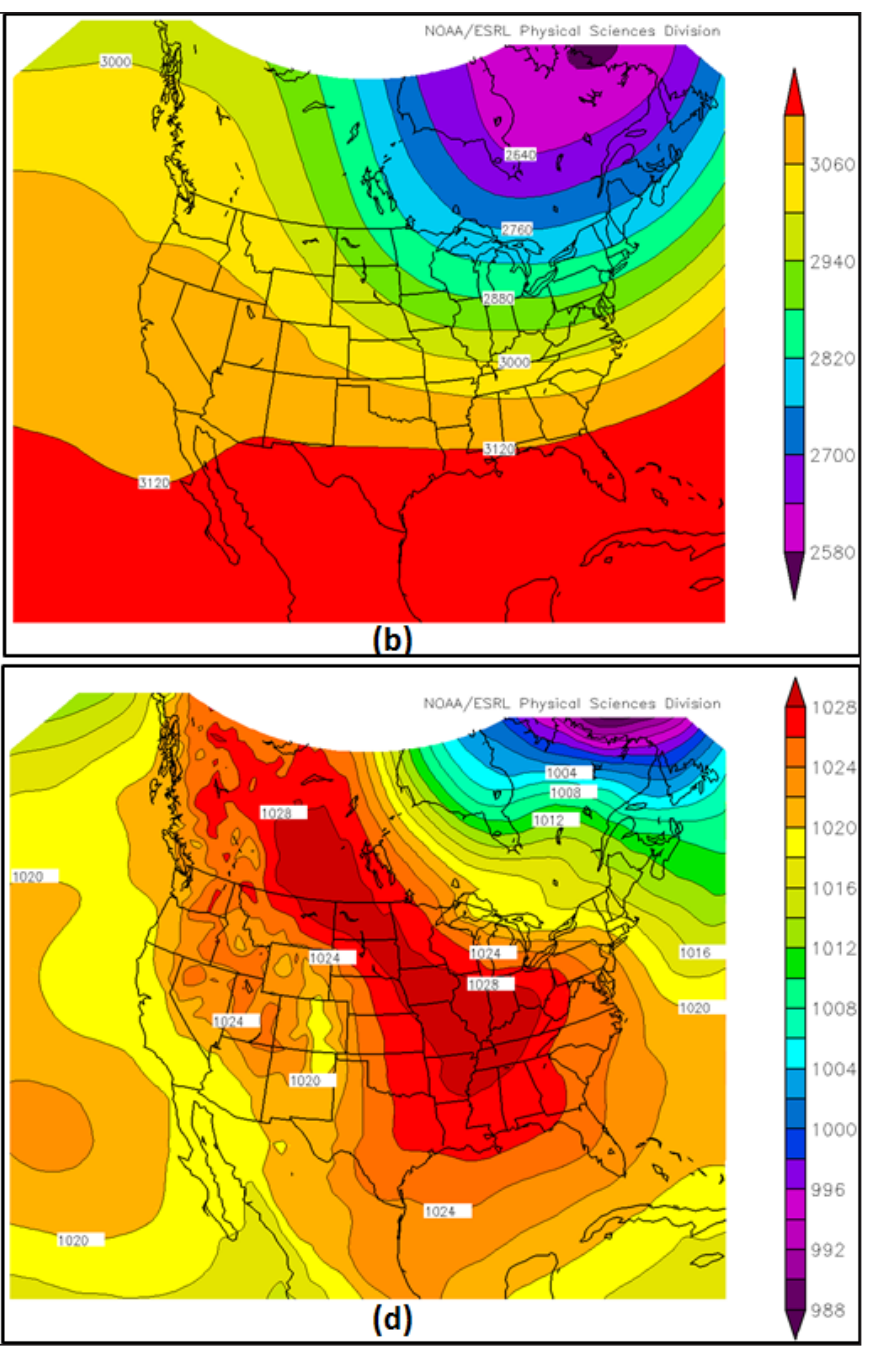

Figure 18. Same as Fig. 17 except for Type B events.

for $\mathrm{MLC}=0$ the equation becomes:

IE $\left(\right.$ or Band Length $\left.{ }^{0.38}\right)=4.781378-0.041242$ (mean ML wind speed $)+0.088804($ surface TdD $)-$ 0.100086 (lake T - air T@850hPa) + 0.030905 $(0-1-\mathrm{km}$ bulk shear $)+0.010518 \quad(0-3-\mathrm{km}$ bulk shear) +0.085037 (top of ML wind speed) -0.048156 (ML bulk shear) $+1.746865 \cos$ (mean ML wind dir. $/ 360 \times 2 \pi)-1.059166 \cos ($ top of ML wind dir. $/ 360 \times 2 \pi$ );

and for $\mathrm{MLC}=1$ the equation becomes:

IE $\left(\right.$ or Band Length $\left.{ }^{0.38}\right)=7.975105+0.009113$ (mean ML wind speed) +0.088804 (surface TdD) - 0.1813 (lake T-air T@850hPa)+0.023536 (lake T - air T@700hPa) - 0.051691 (ML depth) + 0.030905 (0-1-km bulk shear) - 0.006965 (0-3- $\mathrm{km}$ bulk shear) - 0.018952 (top of ML wind speed $)+1.746865 \cos ($ mean ML wind dir. $/ 360 \times 2 \pi)$ $-1.059166 \cos$ (top of ML wind dir. $/ 360 \times 2 \pi)+$ $0.399647 \cos$ (surface wind dir. $/ 360 \times 2 \pi)+0.031865$ (ML bulk shear).

Model assessment measures were finally considered and found satisfactory. The residual SE was 0.6866 on 733 degrees of freedom and the adjusted R2 was 0.731 . The model yields a strong adjusted R2 and it explains $73.1 \%$ of the variation of the response variable. The $\mathrm{SE}$ is low at 0.6866 (close to the minimum among all models) and the AIC is close to the minimum among all models. The CV results try to quantify the predictive ability of the model. What can be seen is that the predictive error (PE, similar to the SE but computed on the test set instead of the training set) has a minimum of 0.6898 , a maximum of 0.7096 , and a mean of 0.6987 . 
Table 5. Output from the selected statistical model, including coefficients, standard error, $\mathrm{t}$ value (coefficient/ standard error), and $\operatorname{Pr}(>|t|)$ (corresponding predictive value of that test). Significant codes for $\operatorname{Pr}(>|t|)$ values: 0

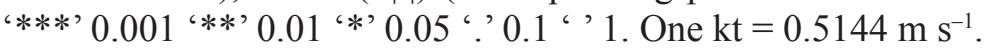

\begin{tabular}{|c|c|c|c|c|}
\hline Output from initial multiple linear regression & Coefficient & Standard Error & $t$ value & $\operatorname{Pr}(>|t|)$ \\
\hline Intercept & 4.781378 & 0.316214 & 15.121 & $<2 \mathrm{e}-16 * * *$ \\
\hline Mean ML wind speed (kt) & -0.041242 & 0.011860 & -3.477 & $0.000536 * * *$ \\
\hline Surface dewpoint depression $\left({ }^{\circ} \mathrm{C}\right)$ & 0.088804 & 0.014841 & 5.984 & $3.41 \mathrm{e}-09 * * *$ \\
\hline Lake - air $\Delta \mathrm{T}$ at $850 \mathrm{hPa}\left({ }^{\circ} \mathrm{C}\right)$ & -0.100086 & 0.012624 & -7.928 & $8.27 \mathrm{e}-15 * * *$ \\
\hline $0-1-\mathrm{km}$ bulk shear $(\mathrm{kt})$ & 0.030905 & 0.004539 & 6.809 & $2.04 \mathrm{e}-11 * * *$ \\
\hline 0-3-km bulk shear (kt) & 0.010518 & 0.003341 & 3.148 & $0.001708 * *$ \\
\hline Wind speed at top of ML (kt) & 0.085037 & 0.012360 & 6.880 & $1.28 \mathrm{e}-11 * * *$ \\
\hline ML bulk shear (kt) & -0.048156 & 0.009171 & -5.251 & $1.99 \mathrm{e}-07 * * *$ \\
\hline $\cos (\mathrm{ML}$ wind direction) & 1.746865 & 0.180769 & 9.664 & $<2 \mathrm{e}-16 * * *$ \\
\hline $\cos ($ Wind direction at top of $\mathrm{ML})$ & -1.059166 & 0.143438 & -7.384 & $4.18 \mathrm{e}-13 * * *$ \\
\hline Existence of MLC & 3.193727 & 0.408011 & 7.828 & $1.74 \mathrm{e}-14 * * *$ \\
\hline Mean ML wind speed $(\mathrm{kt}){ }^{*}$ MLC & 0.050355 & 0.014658 & 3.435 & $0.000625 * * *$ \\
\hline Lake - air $\Delta \mathrm{T}$ at $850 \mathrm{hPa}\left({ }^{\circ} \mathrm{C}\right) * \mathrm{MLC}$ & -0.81214 & 0.021729 & -3.738 & $0.000200 * * *$ \\
\hline Lake - air $\Delta \mathrm{T}$ at $700 \mathrm{hPa}\left({ }^{\circ} \mathrm{C}\right) * \mathrm{MLC}$ & 0.023536 & 0.014181 & 1.660 & 0.097409 \\
\hline ML depth $(\mathrm{km}) *$ MLC & -0.051691 & 0.022373 & -2.310 & $0.021142 *$ \\
\hline 0-3-km bulk shear (kt) ${ }^{*}$ MLC & -0.017483 & 0.004927 & -3.548 & $0.000413 * * *$ \\
\hline $\cos ($ Surface wind direction $) *$ MLC & 0.399647 & 0.121505 & 3.289 & $0.001053 * *$ \\
\hline
\end{tabular}

This indicates that the PE is very close to the SE of the model, and thus the model is performing very well. The increase in error from the training set to the test set increases in a range from $0.46 \%$ to $3.2 \%$, with a mean increase of $1.76 \%$. These are very good performance numbers, indicating a stable model. Output from the selected statistical model is shown in Table 5.

\section{b. Forecasting the existence of a multi-lake connection}

One of the more subjective and difficult aspects of determining IE is forecasting whether or not an MLC will be present. Existence of an MLC can be forecast using some of the techniques developedbased on positions of geopotential height and MSLP minimum centers, or within a general trough or closed low at the surface, $850 \mathrm{hPa}$, and $700 \mathrm{hPa}$. The most favorable position for these minimum centers and troughs associated with the presence of an MLC is generally over south-central Quebec, and tracking in a northeastward direction. Trajectories associated with these favorable trough positions depict a cyclonic flow regime, with connection to upstream moisture sources from Georgian Bay, Lake Huron, or even Lake Superior. Detecting the possible existence of an MLC can be done by using observational tools such as satellite and radar, but this limits the lead time because it requires upstream LES activity to have already developed. To achieve increased lead time, application of techniques using numerical weather prediction output to assess moisture pre-conditioning and wind trajectories is necessary, as well as using model-simulated reflectivity to check for the existence of an MLC.

\section{Summary}

This research sought to (i) identify which atmospheric parameters commonly have the greatest influence on the IE of LES bands and (ii) develop forecasting techniques to assist meteorologists. This was accomplished by first defining three categories for IE (short, moderate, long) based on quartiles of IE lengths for each time step. Then several meteorological parameters (based on previous LES research) were analyzed using statistical correlations at data points within, and just outside of, LES bands - based on 12$\mathrm{km}$ NAM analysis soundings and observed soundings at ALB and BUF. Box-and-whiskers plots were created for each parameter, separated by IE category, to determine which values are important to variation in IE.

The most strongly correlated parameters to IE included existence of an MLC, lake-air temperature differentials, $0-1-\mathrm{km}$ bulk shear, and mean wind speed within the ML. Favorable environments for long IE were categorized as Type A, and were characterized by existence of an MLC and conditional instability. Favorable environments for short IE were categorized as Type B, and were characterized by the lack of an MLC and moderate to extreme instability. Composites for both Type A and B environments were constructed to show differences in the height fields at 500, 700, and $850 \mathrm{hPa}$, as well as MSLP. 
Finally, a predictive equation for forecasting IE of LES downwind of Lake Ontario was developed from a statistical model using stepwise and backwards selection algorithms. The skill of the equation was determined by $\mathrm{CV}$ methods. Based on the favorable $\mathrm{CV}$ results, this equation can be used operationally based on forecast soundings proximal to LES bands to predict eventual IE given favorable conditions for LES.

\section{Future Work}

A real-time application using results from the IE predictive equation is in development to automate calculations in the equation based on the selected parameters. Data from forecast proximity soundings can be used to compute most of the terms in the equation, except for the MLC. Determining the existence of an MLC would need to be done by the forecaster using techniques discussed in this manuscript and would be a simple yes (1) or no (0) term in the equation. The addition of a graphical dimension from the output of the equation also is in development. The predicted IE would be shown on a map for a particular wind vector and would be helpful to operational forecasters in visualizing the output (versus simply seeing a raw distance in mileage).

The equation and application also could, over time, be adapted to other portions of the Great Lakes region. As such, the results of this research could ultimately prove beneficial for WFOs affected by LES from Lakes Erie, Huron, Michigan, and Superior. Mann et al. (2002) determined that interactions from upstream Lake Superior had an influence on the translation, intensity, and morphology of LES bands over Lake Michigan. Investigating the effects of ice cover also would have potential implications for LES bands and MLC across the upper Great Lakes.

A final area for future work that would be beneficial to forecasters would be to investigate how accurate various new high-resolution forecast models are in simulating IE of LES bands. Since this research was completed, new high-resolution models such as the 3-km HRRR and local WRF models have become operational. These high-resolution models may be able to more realistically simulate LES bands. Highresolution ensembles also may have some application in predicting IE and are another possible avenue for investigation. Comparing predicted IE from the equation developed in this paper versus IE predicted by high-resolution models (15-dBZ threshold from simulated reflectivity) could further test the utility of techniques developed in this paper.

Acknowledgements. The authors thank Heather Reeves from the National Weather Association for being the review coordinator for this paper at the Journal of Operational Meteorology, as well as three anonymous reviewers for their intuitive and thorough reviews. The authors thank Michael Evans from NOAA/NWS Binghamton, New York, for reviewing the initial draft of this document and for his insightful comments and suggestions. The authors also thank Brian Miretzky from NOAA/NWS Eastern Region for being the overall editor and contact for this document and for providing helpful guidance. Two anonymous reviewers from NOAA/NWS Eastern Region also were instrumental in improving this document by their thorough reviews and intuitive suggestions. The authors thank Warren Snyder from NOAA/NWS Albany, New York, for reviewing this document. A few students from the State University of New York at Albany were instrumental in sampling hundreds of sounding points for calculations of parameters. Finally, the authors acknowledge the work of State University of New York at Albany graduates Hannah Attard and Jason Krekeler.

\section{REFERENCES}

Akaike, H., 1972: Use of an information theoretic quantity for statistical model identification. Proceedings of the Fifth International Conference on System Sciences, North Hollywood, CA, Western Periodicals, 249-250.

Alexander, C. R., S. S. Weygandt, T. G. Smirnova, S. Benjamin, P. Hofmann, E. P. James, and D. A. Koch, 2010: High Resolution Rapid Refresh (HRRR): Recent enhancements and evaluation during the 2010 convective season. Preprints, 25th Conf. on Severe Local Storms, Denver, CO, Amer. Meteor. Soc., 9.2. [Available online at https://ams.confex.com/ams/25SLS/ techprogram/paper $175722 . \mathrm{htm}$.]

Ballentine, R. J., and D. Zaff, 2007: Improving the understanding and prediction of lake-effect snowstorms in the eastern Great Lakes region. Final Rep. to the COMET Outreach Program Award S06-58395, 41 pp. , A. J. Stamm, E. E. Chermack, G. P. Byrd, and D. Schleede, 1998: Mesoscale model simulation of the 4-5 January 1995 lake-effect snowstorm. Wea. Forecasting, 13, 893-920, Crossref.

Banacos, P. C., 2011: Box and whisker plots for local climate datasets: Interpretation and creation using Excel 2007/2010. NOAA/NWS ER Tech. Attach. 2011-01, 20 pp. [Available online at www.weather.gov/media/erh/ 
ta2011-01.pdf.]

Box, G. E. P. and D. R. Cox, 1964: An analysis of transformations (with discussion). J. Roy. Stat. Soc., 26, 211-252.

Breiman, L., 1988: Submodel selection and evaluation in regression. The conditional case and little bootstrap. U.C. Berkeley Tech. Rep. No.169. , and P. Spector, 1992: Submodel selection and evaluation in regression: The X-random case. Int. Stat. Rev., 60, 291-319, Crossref.

Brown, R. A., T. A. Niziol, N. R. Donaldson, P. I. Joe, and V. T. Wood, 2007: Improved detection using negative elevation angles for mountaintop WSR-88Ds. Part III: Simulations of shallow convective activity over and around Lake Ontario. Wea. Forecasting, 22, 839-852, Crossref.

Byrd, G. P., R. A. Anstett, J. E. Heim, and D. M. Usinski, 1991: Mobile sounding observations of lake-effect snowbands in western and central New York. Mon. Wea. Rev., 119, 2323-2332, Crossref.

Campbell, L. S., W. J. Steenburgh, P. G. Veals, T. W. Letcher, J. R. Minder, 2016: Lake-effect mode and precipitation enhancement over the Tug Hill Plateau during OWLeS IOP2b. Mon. Wea. Rev., 144, 1729-1748, Crossref.

Davison, A. C., and D. V. Hinkley, 1997: Bootstrap methods and their application. Cambridge University Press, $582 \mathrm{pp}$.

Dockus, D. A., 1985: Lake-effect snow forecasting in the computer age. Natl. Wea. Dig., 10 (4), 5-19. [Available online at nwafiles.nwas.org/digest/papers/1985/Vol10Issue4-Nov1985/Pg5-Dockus.pdf.]

Evans, M. S., and R. B. Wagenmaker, 2000: An examination of an intense west-east oriented lake-effect snow band over southeast lower Michigan. Natl. Wea. Dig., 24 (1-2), 67-78. [Available online at nwafiles.nwas.org/ digest/papers/2000/Vol24No12/Pg67-Evans.pdf.]

Fisher, R. A., 1925: Statistical methods for research workers. Genesis Publishing Pvt Ltd, 336 pp.

Fox, J., 2008: Applied Regression Analysis and Generalized Linear Models. 2nd ed. Sage Publication, 688 pp.

Glass, G. V., and K. D. Hopkins, 1995: Statistical Methods in Education and Psychology. 3rd ed. Allyn and Bacon, $472 \mathrm{pp}$.

Hastie, T., R. Tibshirani, and J. Friedman, 2009. The Elements of Statistical Learning: Data Mining, Inference, and Prediction. 2nd ed. Springer, 745 pp.

Hjelmfelt, M. R., 1990: Numerical study of the influence of environmental conditions on lake-effect snowstorms over Lake Michigan. Mon. Wea. Rev., 118, 138-150, Crossref.

Holroyd, E. W., III, 1971: Lake-effect cloud bands as seen from weather satellites. J. Atmos. Sci., 28, 1165-1170, Crossref.

Kristovich, D., and Coauthors, 2016: The Ontario Winter Lake-effect Systems (OWLeS) Field Campaign:
Scientific and educational adventures to further our knowledge and prediction of lake-effect storms. Bull. Amer. Meteor. Soc., in press, Crossref.

Kutner, M. H., C. J. Nachtsheim, and J. Neter, 2004: Applied Linear Regression Models, 4th ed. McGraw-Hill, $701 \mathrm{pp}$.

Lavoie, R. L., 1972: A mesoscale numerical model of lakeeffect storms. J. Atmos. Sci., 29, 1025-1040, Crossref.

Magsig M. A., N. M. Said, N. Levit, and X. Yu, 2004: The Weather Event Simulator and opportunities for the severe storms community. Preprints, 22nd Conf. on Severe Local Storms, Hyannis, MA. Amer. Meteor. Soc., P2.1. [Available online at ams.confex.com/ams/ pdfpapers/82007.pdf.]

Mann, G. E., R. B. Wagenmaker, and P. J. Sousounis, 2002: The influence of multiple lake interactions upon lake effect storms. Mon. Wea. Rev., 130, 1510-1530, Crossref.

Mesinger, F., and Coauthors, 2006: North American Regional Reanalysis. Bull. Amer. Meteor. Soc., 87, 343-360, Crossref.

Minder, J. R., T. W. Letcher, L. S. Campbell, P. G. Veals, and W. J. Steenburgh, 2015: The evolution of lake-effect convection during landfall and orographic uplift as observed by profiling radars. Mon. Wea. Rev., 143, 4422-4442, Crossref.

Niziol, T. A., 1987: Operational forecasting of lake effect snowfall in western and central New York. Wea. Forecasting, 2, 310-321, Crossref.

, W. R. Snyder, and J. S. Waldstreicher, 1995: Winter weather forecasting throughout the eastern United States. Part IV: Lake effect snow. Wea. Forecasting, 10, 61-77, Crossref.

NWS, cited 2015: National Weather Service Weather-Ready Nation Roadmap. [Available online at www.nws.noaa. gov/com/weatherreadynation/files/nws wrn roadmap final april17.pdf.]

Peace, R. L., Jr., and R. B. Sykes Jr., 1966: Mesoscale study of a lake effect snow storm. Mon. Wea. Rev., 94, 495-507, Crossref.

Picard, R. R., and R. D. Cook, 1984: Cross-validation of regression models. J. Amer. Stat. Assoc., 79, 575-583, Crossref.

Rizopoulos, D., 2006: 1tm: An R package for latent variable modeling and item response theory analyses. J. Stat. Softw., 17 (5), 1-25, Crossref.

Rogers, E., B. Ferrier, Z. Janjic, W. S. Wu, and G. DiMego, 2014: The NCEP North American Mesoscale (NAM Analysis and Forecast System: Near-term plans and future evolution into a high-resolution ensemble. Preprints, 22nd Conf. on Numerical Weather Prediction, Atlanta, GA, Amer. Meteor. Soc., J1.3 [Available online at ams.confex.com/ams/94Annual/webprogram/ Paper238898.html.]

Shao, J., 1993: Linear model selection by cross-validation. 
J. Amer. Stat. Assoc., 88, 486-494, Crossref.

, 1997: An asymptotic theory for linear model selection. Statistica Sinica, 7, 221-264.

Skamarock, W. C., and Coauthors, 2008: A description of the Advanced Research WRF version 3. NCAR Tech Note TN-475+STR, 125 pp. [Available online at www2.mmm.ucar.edu/wrf/users/docs/arw v3.pdf.]

Steiger, S. M., and Coauthors, 2013: Circulations, bounded weak echo regions, and horizontal vortices observed within long-lake-axis-parallel-lake-effect storms by the Doppler on Wheels. Mon. Wea. Rev., 141, 2821-2840, Crossref.

Super, A. B., and E. W. Holroyd III, 1996: Snow accumulation algorithm for the WSR-88D radar, version 1. U.S. Dept. of Interior/Bureau of Reclamation Rep. R-96-04, 143 pp. [Available online at www.usbr.gov/tsc/techreferences/ rec/R9604.pdf.]

Sykes, R. B., Jr., 1966: The blizzard of '66 in central New York State-Legend in its time. Weatherwise, 19, 240-247, Crossref.

Veals, P. G., and W. J. Steenburgh, 2015: Climatological characteristics and orographic enhancement of lakeeffect precipitation east of Lake Ontario and over the Tug Hill Plateau. Mon. Wea. Rev., 143, 3591-3609, Crossref.

Venables, W. N. and B. D. Ripley, 2002: Modern Applied Statistics with $S$. 4th ed. Springer, 498 pp, Crossref.

Wiggin, B. L., 1950: Great snows of the Great Lakes. Weatherwise, 3, 123-126, Crossref.

Wilks, D. S., 2006: Statistical Methods in the Atmospheric Sciences. 2nd ed. Academic Press, 648 pp.

Wright, D. M., D. J. Posselt, and A. L. Steiner, 2013: Sensitivity of lake-effect snowfall to lake ice cover and temperature in the Great Lakes region. Mon. Wea. Rev., 141, 670-689, Crossref. 